\title{
Capitalization of the Single Payment Scheme into Land Value: Generalized Propensity Score Evidence from the European Union
}

\author{
Jerzy Michalek, Pavel Ciaian, and d'Artis Kancs
}

\begin{abstract}
This paper estimates the capitalization of the single payment scheme (SPS) into land values. The theory suggests a nonlinear and discontinuous relationship between the SPS and land rents. In empirical analysis we employ unique farm-level panel data and apply the generalized propensity score matching approach. Our estimates suggest a $6 \%$ to $10 \%$ SPS capitalization rate. On average in the European Union, the nonfarming landowners' gains from the SPS are only 4\%. However, there is a large variation in the capitalization rate for different SPS levels and between different member states (3\% to 94\%). (JEL H23, Q15)
\end{abstract}

\section{INTRODUCTION}

Annually, the European Union spends around $€ 55$ billion on the Common Agricultural Policy (CAP), with the aim of supporting farmers' income and producing agricultural public goods like landscape and a clean environment. The majority of the CAP subsidies are disbursed in the form of decoupled direct payments, the so-called single payment scheme (SPS), which are not linked to current or future production but depend solely on past production levels. The SPS accounts for more than $50 \%$ of the annual CAP expenditures.

Farm income effects of agricultural policy, which Alston and James (2002) refer to as the "incidence of agricultural policy," have been studied extensively in the theoretical literature. Alston and James (2002), de Gorter and Meilke (1989), Dewbre, Anton, and Thompson (2001), Gardner (1983), and Guyomard, Le Mouël, and Gohin (2004) have analyzed how income distributional effects differ between subsidy types, specifically, coupled ver-

Land Economics • May 2014 • 90 (2): 260-289

ISSN 0023-7639; E-ISSN 1543-8325

(C) 2014 by the Board of Regents of the

University of Wisconsin System sus decoupled. Desquilbet and Guyomard (2002) and Sheldon, Pick, and McCorriston (2001) have analyzed how income distributional effects differ between the agents along the vertical chain. McCorriston and Sheldon (1991), Salhofer and Schmid (2004), and Ciaian and Swinnen $(2006,2009)$ have analyzed how income distributional effects depend on output and input market imperfections and transaction costs. Finally, de Gorter (1992) and Munk (1994) have analyzed how they depend on policy implementation details.

The overall finding of the empirical literature is that not only farmers but also landowners benefit from agricultural subsidies. According to Goodwin, Mishra, and OrtaloMagné (2003), Weersink et al. (1999), Lence and Mishra (2003), Roberts, Kirwan, and Hopkins (2003), Kirwan (2009), Ciaian and Kancs (2012), Barnard et al. (1997), and Patton et al. (2008), the capitalization rate of $\mathrm{Cou}_{\text {- }}$ pled subsidies into land values varies between $20 \%$ and $100 \%$, whereas the capitalization rate of decoupled subsidies is usually found to be lower, namely, between $20 \%$ and $80 \%$.

Most of the existing empirical studies are on North America (the United States and Canada); only a few cover the European Union (Patton et al. 2008; Breustedt and Habermann 2011; Ciaian and Kancs 2012). In contrast to other types of farm subsidies, the empirical evidence on the SPS capitalization in the European Union is very limited. Kilian et al. (2012) study the capitalization of the SPS in Bavaria in Germany and find that the SPS is capitalized by an additional $15 \%$ to $19 \%$ on top of the previous coupled subsidies. How-

The authors are, respectively, independent researcher, Kiel, Germany; scientific officer; and senior scientist, European Commission DG Joint Research Centre, Seville, Spain. 
ever, Kilian et al. (2012) use traditional estimation techniques (ordinary least squares and instrumental variable estimators) and only cross-section data (2005, which is the first year of the SPS implementation). Thus, they are not able to control for several key econometric issues, such as endogeneity, general equilibrium effects, and selection bias, implying that their estimates might be biased.

Our main contribution to the literature is to provide the first estimates of the SPS capitalization rate into farmland rental prices in the European Union. First, we discuss theoretically how the SPS may affect land rents. In order to test the theoretical predictions empirically, we employ the generalized propensity score (GPS) matching approach of Hirano and Imbens (2004), which allows us to address several important sources of bias, from which previous studies suffer. In particular, by employing the GPS matching approach we are able to address the selection bias, the simultaneity bias, the general equilibrium effects, and possible misspecification of the functional form. In addition, this technique allows us to estimate the policy incidence for different SPS levels and, hence, to obtain more reliable estimates of variation in the SPS capitalization rates.

\section{SPS IN THE EUROPEAN UNION}

Under the Word Trade Organization (WTO) rules, the decoupled subsidies (referred to as Green Box measures), which do not distort production or at most cause minimal distortion, are allowed without limits, whereas the coupled subsidies, which are production distorting (referred to as Amber Box measures), are subject to displacement (WTO 2003). In response to pressure from the WTO, which claimed that the European Union was providing an unfair competitive advantage by supporting its agricultural sector, the CAP was significantly reformed in 2003. The previous CAP subsidy system (Agenda 2000), based on coupled area and animal payments, was replaced by the decoupled SPS starting from 2005. The aim was to shift agricultural support toward nondistortive polices. The SPS is allocated as a fixed set of payments per farm independent of production level. Farms are entitled to yearly payments, depending on the amount of the SPS entitlements and the eligible area of land.

When implementing the SPS, the E.U. member states could choose between three different SPS implementation models: the historical model, the regional model, and the hybrid model. Under the historical model, the SPS is farm specific and equals the support the farm has received in the "reference" period. Under the regional model, an equal per hectare payment is granted to all farms in a given region. The hybrid model is a combination of the historical and regional models and has two versions: static and dynamic. The key difference between the three models is in the unit value of entitlements: under the historical and hybrid models, the value of entitlement varies between farms (stronger in the former than in the latter), whereas under the regional SPS model, all farms in a given region received entitlements with the same unit value. The main source of variation is the past (production) coupled subsidies, which determine the SPS value at farm level fully in the historical model and partially in the hybrid model. The most commonly implemented SPS model in the European Union is the historical model, ${ }^{1}$ whereas none of the studied member states implemented the regional model. This has important implications for econometric estimations, suggesting that farm-level data may provide sufficient variation to identify differences in the unit value of the SPS among farms.

In the first year of the SPS implementation (2005 or 2006 , depending on the country), ${ }^{2}$

\footnotetext{
${ }^{1}$ In 2007 the historical model was implemented in Austria, Belgium, France, Greece, Ireland, Italy, the Netherlands, Portugal, and Spain; the regional model in Malta and Slovenia; the static hybrid in Denmark, Luxembourg, and Sweden; the dynamic hybrid in Finland and Germany; and a mixed system of historical and hybrid models in the United Kingdom. Those member states implementing the dynamic hybrid model move gradually to a fully regional model. In member states implementing the static hybrid model, the regional and the historical shares do not change over time (European Commission 2007).

${ }^{2}$ Member states could choose to introduce the SPS either in 2005 or in 2006. The data used in this paper covers the period before and after the introduction of SPS in all the original 15 member states (EU-15). The EU-15 include Austria, Belgium, Denmark, Finland, France, Germany, Greece,
} 
each farm was allocated a fixed amount of the SPS entitlements. Farms can activate the entitlements and receive the SPS if they are accompanied by an equal area of eligible land. ${ }^{3}$ This implies that the SPS is indirectly linked to land because, in the absence of land, farms cannot activate (cash in) the SPS entitlements. However, the SPS is not linked to a specific land area-the SPS entitlements can be activated by any eligible farmland in the region. Furthermore, farms can expand or decrease their stock of entitlements by buying or selling entitlements on the market from other farms.

Farm eligibility to the SPS is subject to cross-compliance. Each farm that receives the SPS must comply with the statutory management requirements (SMR) and maintain the agricultural land in good agricultural and environmental condition (GAEC). The SMR are based on preexisting E.U. directives and regulations in the fields of the environment; public, animal, and plant health; and animal welfare. The aim of the GAEC is to prevent the abandonment and severe undermanagement of agricultural land.

\section{THE IMPACT OF THE SPS ON FARMLAND RENTS: A THEORETICAL PERSPECTIVE}

\section{Factors Influencing the SPS Capitalization Level}

According to theoretical studies, the key factors determining the level of capitalization of SPS into land values are the allocated stock of entitlements, type of SPS model, and crosscompliance costs. Capitalization might be also impacted by rigidities and region-specific factors, such as credit market imperfections,

Ireland, Italy, Luxemburg, the Netherlands, Portugal, Spain, Sweden, and United Kingdom.

3 This setting makes the SPS a different type of subsidy compared to the coupled area payment implemented prior to the SPS introduction. Under the coupled area payment, farms receive payments for the entire area they use for eligible crops, whereas with the SPS only a predefined quantity of land (determined by the number of entitlements) may obtain payments. Further, the value of coupled area payment does not vary by farm. All farms receive the same value of payment for a given eligible crop in a given region. social capital, and formal and informal land institutions (Courleux et al. 2008; Kilian and Salhofer 2008; Ciaian, Kancs, and Swinnen 2008, 2010).

To illustrate the SPS capitalization, we use the model of Ciaian and Swinnen (2006) and Ciaian, Kancs, and Swinnen (2008). Agricultural goods are produced by two types of farms,${ }^{4}$ which permit the SPS variation across farms to be accounted for. The total agricultural land $\left(A^{\mathrm{T}}\right)$ is assumed to be owned by landowners, who rent it to farmers. ${ }^{5}$

The land market is illustrated in Figure 1. The horizontal axis shows the quantity of land, and the amount of land rented by farm $1\left(A^{1}\right)$ is shown from the left to right on the horizontal axis, whereas the amount of land rented by farm $2\left(A^{2}\right)$ is shown from the right to left with $A^{2}=A^{\mathrm{T}}-A^{1}$. The vertical axis measures the rental price and subsidies. The initial land demands of farm 1 and farm 2 are given by downward sloping curves $D^{1}$ and $D^{2}$, respectively. Without the SPS, the equilibrium set of land allocation and land rent is $\left(A^{*}, w^{*}\right)$. In equilibrium, farm 1 rents $A^{*}$ ha of land $\left(A^{1}=A^{*}\right)$ and farm 2 rents $A^{2}=A^{\mathrm{T}}-A^{*}$ ha of land.

Denote the endowment of the SPS entitlements of type 1 owned by farm 1 by $A_{\mathrm{E}}^{1}$, and its unit face value by $t^{1}$. Analogously, $A_{\mathrm{E}}^{2}$ $\left(=A^{\mathrm{T}}-A_{\mathrm{E}}\right)$ is the endowment of entitlements of type 2 owned by farm 2 , and $t^{2}$ is its unit face value (Figure 1). The total endowment of entitlements, $A_{\mathrm{E}}^{1}+A_{\mathrm{E}}^{2}$, may or may not exceed the total land, $A^{\mathrm{T}}$, implying that they may be in surplus, $A_{\mathrm{E}}^{1}+A_{\mathrm{E}}^{2}>A^{\mathrm{T}}, 6$ or in deficit, $A_{\mathrm{E}}^{1}+$ $A_{\mathrm{E}}^{2}<A^{\mathrm{T}}$.

The SPS creates kinks in the land demand functions of farms. Farms do not benefit from the SPS for the land that they rent above the amount of the entitlements they own, that is,

${ }^{4}$ A similar approach was applied by Courleux et al. (2008), by assuming two profit-maximizing producers in the agricultural economy.

5 This distinction between landowners and farmers is convenient for our explanation but is not essential for the analysis and the derived results.

${ }^{6}$ Several factors may lead to a situation where the number of entitlements exceeds the eligible area in the intermediate run. For example, agricultural land conversion to nonagricultural use, or the allocation of new entitlements to farms (e.g., entrants). 


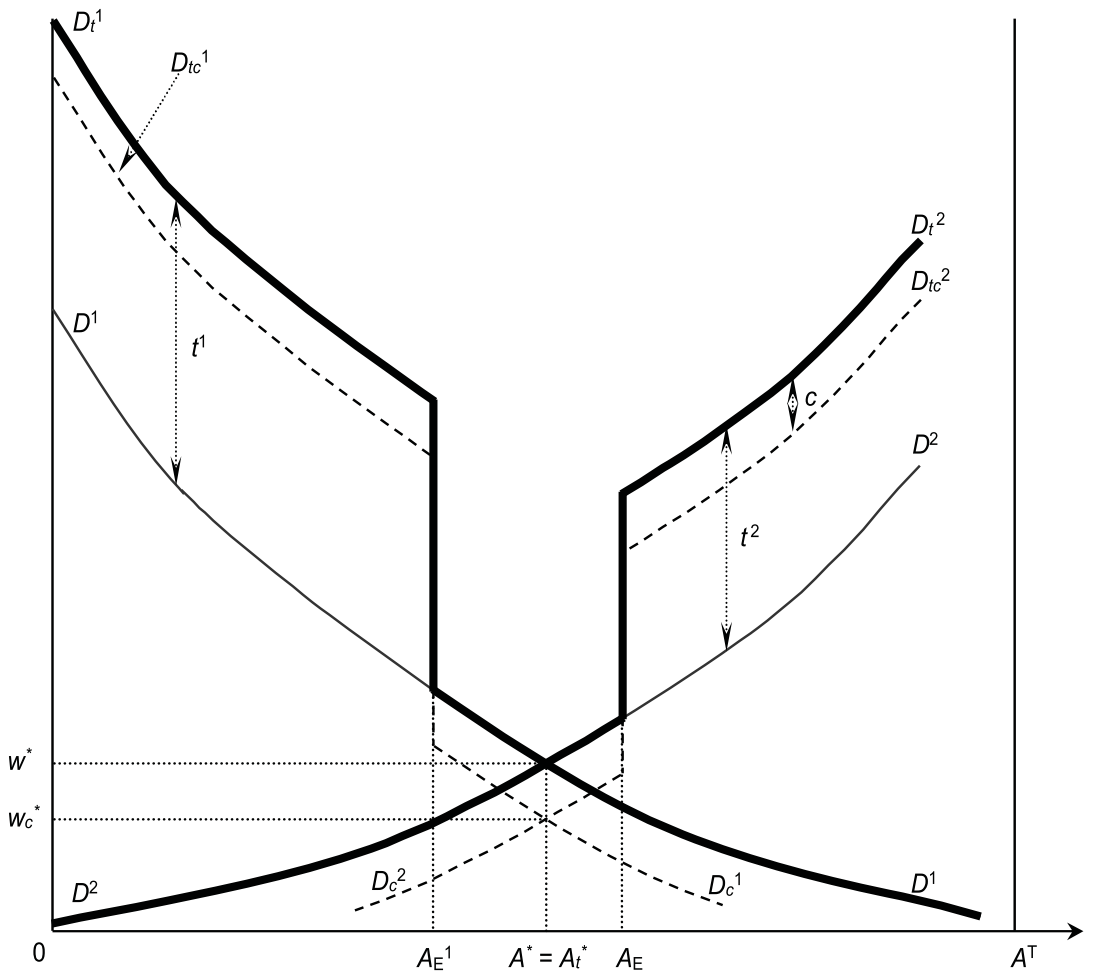

FIGURE 1

The Effect of the Single Payment Scheme with Deficit Entitlements

above $A_{\mathrm{E}}^{1}$ and $A_{\mathrm{E}}^{2}\left(=A^{\mathrm{T}}-A_{\mathrm{E}}\right)$ for farm 1 and farm 2 , respectively. ${ }^{7}$ In this case, farm $i$ 's willingness to pay for land is not affected by the SPS. For additional land farm $i$ cannot pay more than the marginal profitability of land. In the reverse case, when farm $i$ rents less land than its eligible area $A_{\mathrm{E}}^{i}$, the marginal profitability of land is increased by the value of entitlement, $t^{i}$. Now farms are willing to pay a higher rent, up to $t^{i}$. Otherwise, the payment is lost to farms. Graphically, the introduction of the SPS is illustrated in Figure 1. Starting from the left-hand side and following the bold full lines, the land demand with SPS is given

${ }^{7} A_{\mathrm{E}}$ is used as support to indicate on the horizontal axes the stock of type 2 entitlements given that the area and entitlements of farm 2 are measured from right to left in the figures. by $D_{t}^{1} D^{1}$ and $D^{2} D_{t}^{2}$ for farms 1 and 2 , respectively. ${ }^{8}$

\section{Land Entitlements}

According to Courleux et al. (2008), Kilian and Salhofer (2008), and Ciaian, Kancs, and Swinnen (2008), the capitalization rate of the SPS largely depends on the ratio of the eligible area to the total number of entitlements. In the case of deficit entitlements relative to the eligible area the SPS benefits farms, it is not capitalized into land values. However, if there is a surplus in entitlements, then the SPS is capitalized into land values. For the sake of tractability, we illustrate the two extreme

\footnotetext{
${ }^{8}$ The rest of the variables in Figure 1 are explained in the following sections.
} 


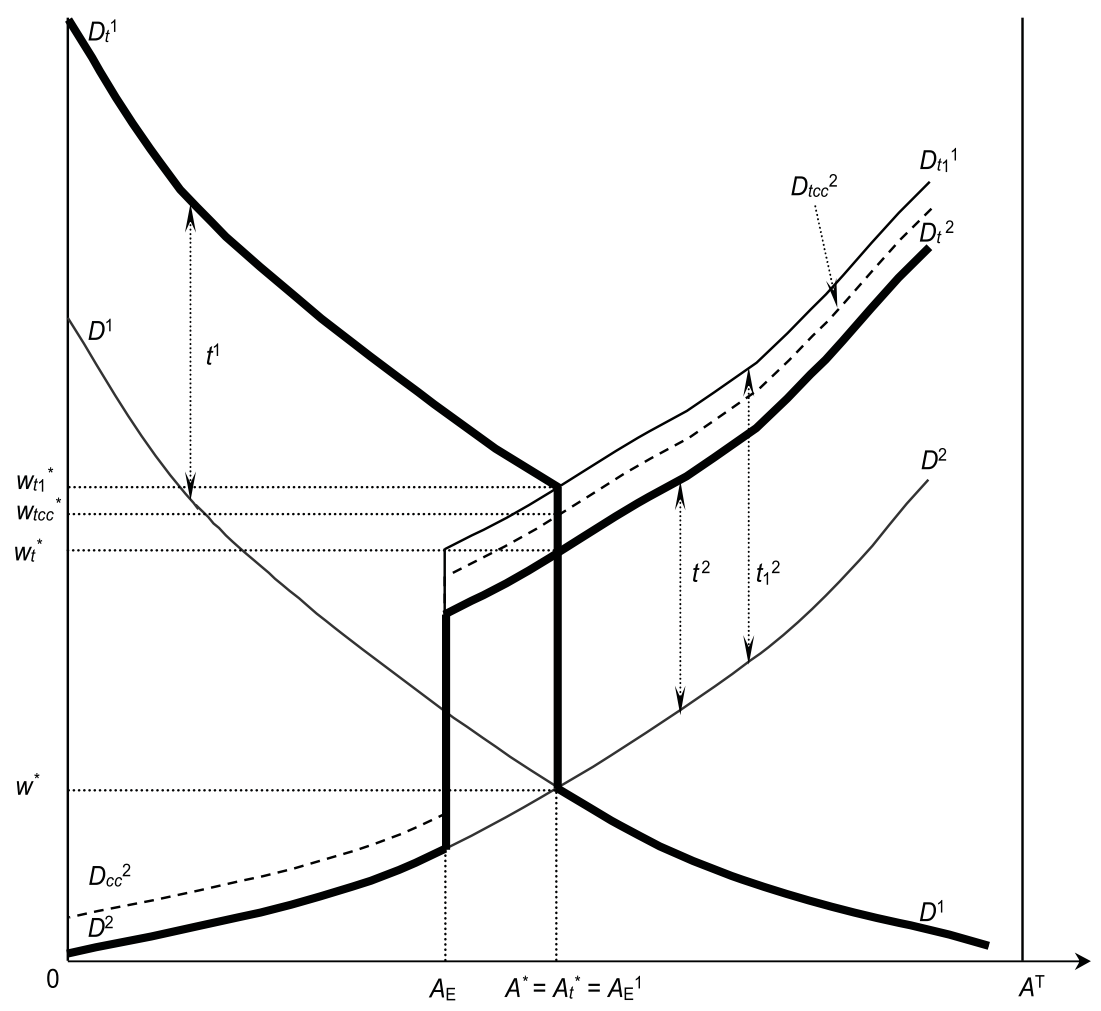

FIGURE 2

The Effect of the Single Payment Scheme with Surplus Entitlements and Credit Market Imperfections

cases, but the results also hold for the intermediate case. ${ }^{9}$

The deficit entitlement stock effect is shown in Figure 1. The land demands without the SPS are $D^{1} D^{1}$ and $D^{2} D^{2}$, and the land market equilibrium is at $\left(A^{*}, w^{*}\right)$. The SPS shifts them to $D_{t}^{1} D^{1}$ and $D^{2} D_{t}^{2}$, for farm 1 and farm 2 , respectively. This implies that with deficit entitlements the equilibrium with and without the SPS is the same at $\left(A^{*}, w^{*}\right)$. Both the equilibrium land demand and prices are not affected by the SPS. The SPS has a zero-distortive marginal effect on farm rental decisions. This implies zero capitalization of the SPS.

Under the surplus entitlements, farms 1 and 2 receive entitlements such that $A_{\mathrm{E}}^{1}+A_{\mathrm{E}}^{2}>$ $A^{\mathrm{T}}$, as shown in Figure 2. Land demands without the SPS are $D^{1} D^{1}$ and $D^{2} D^{2}$ for farms

\footnotetext{
${ }^{9}$ With the intermediate case we mean the situation where the entitlement stock is equal to the eligible area.
}

1 and 2, respectively. The SPS entitlements $t^{1}$ and $t^{2}$ shift their respective land demands to $D_{t}^{1} D^{1}$ and $D^{2} D_{t}^{2}$, and the equilibrium shifts from $\left(A^{*}, w^{*}\right)$ to $\left(A_{t}^{*}, w_{t}^{*}\right)$. In equilibrium, the rental price increases by $w_{t}^{*}-w^{*}$, meaning that the SPS is reflected in higher rents. Hence, under the excess stock of entitlements, the SPS is capitalized into land rents. The main intuition behind these results is that, in the presence of surplus entitlements, farms will not be able to activate all their entitlements with the current area of land. Profitmaximizing farms will compete for additional land, seeking to activate their unused entitlements. Competing farms will overbid the market price for land until it equals the marginal profitability and the entitlement value. As a result, the SPS will be capitalized into land rents. The effect of competitive pressure in the case of deficit entitlement is the reverse. If land is in surplus relative to entitlements, 
farmers will compete for entitlements to benefit from the SPS. As illustrated in Figure 1, the SPS will benefit the entitlement owners, but will not be reflected in higher land rental prices.

\section{SPS Implementation Model}

Theoretical studies have shown that the SPS capitalization level depends significantly on the SPS implementation model (i.e., on the variability of entitlement value between farms): the larger the SPS variation between farms (i.e., historical vs. hybrid SPS model), the lower the capitalization rate of the SPS may be (Courleux et al. 2008; Kilian and Salhofer 2008; Ciaian, Kancs, and Swinnen 2008).

Consider the hybrid/historical SPS models. Under these models entitlement face values differ between farms, $t^{1} \neq t^{2}$, where $t^{1}>t^{2}$. As illustrated in Figure 2, for surplus entitlements the equilibrium capitalization with $t^{1}$ and $t^{2}$ is $w_{t}^{*}-w^{*}$. High-value entitlement, $t^{1}$ $\left(>t^{2}\right)$, is partly reflected in higher rents $\left(w_{t}^{*}-w^{*}<t^{1}\right)$, whereas low-value entitlement, $t^{2}$, is fully incorporated into land values $\left(w_{t}^{*}-w^{*}=t^{2}\right)$. The capitalization level of the SPS, expressed in monetary terms, $w_{t}^{*}-w^{*}$, is equal for both entitlements. However, the capitalization rate, expressed per unit of the SPS, is lower for high-value entitlements. This is because the low-value entitlements determine the SPS capitalization. In equilibrium all farms will pay a rent higher by the value of low-value entitlements, although the willingness to pay for land is higher for farms possessing high-value entitlements compared to farms possessing low-value entitlements. The competition for land will lead to a situation where farms with high-value entitlements will always outcompete farms owning lowvalue entitlements. In equilibrium it is sufficient for farms owning high-value entitlements to pay a rent higher by the value of low-value entitlements, as this is the maximum afforded by and minimum needed to outcompete farms possessing low-value entitlements. Hence, farms owning low-value entitlements will use fully their entitlement to compete for land, and thus the low-value en- titlements determine the SPS capitalization at the margin.

Reducing the variation in the entitlement value across farms, the value of low-value entitlement increases, causing higher SPS capitalization. In the extreme with the regional SPS model, where entitlement values are equal across all farms, the capitalization is highest. For illustrative purpose consider entitlements $t^{1}$ and $t_{1}^{2}$, where $t^{1}=t_{1}^{2}$. Land demands are $D_{t}^{1} D^{1}$ and $D_{t 1}^{2} D^{2}$, and market equilibrium is at $\left(A^{*}, w_{t 1}^{*}\right)$, implying that both entitlements are fully incorporated into higher land values, $w_{t 1}^{*}-w=t^{1}=t_{1}^{2}$ (Figure 2 ). The equalization of entitlement face value rips away the policy gains of farms possessing high-value entitlements, and full SPS value goes to landowners. This implies that the hybrid SPS model leads to higher capitalization than the historical models, as the variation in entitlement value is lower in the former compared to the latter.

\section{Cross-compliance}

According to Ciaian, Kancs, and Swinnen (2010), a further important determinant of SPS capitalization is the conditionality of the SPS. In the European Union, farm eligibility for the SPS is subject to cross-compliance. Given that the cross-compliance requirements impose additional costs to land use, the net effect of the SPS on rental prices is expected to be lower than in the absence of these implementation requirements. In other words, farms' marginal return from land is reduced by cross-compliance costs, which reduces the willingness to pay for rent, causing a downward adjustment in land rents. In Figure 3, with surplus entitlements $t^{1}$ and $t^{2}$, positive cross-compliance costs, $c$, shift the land demand curves downward from $D_{t}^{1} D^{1}$ and $D_{t}^{2} D^{2}$ to $D_{t c}^{1} D_{c}^{1}$ and $D_{t c}^{2} D_{c}^{2}$ (dotted lines), for farm 1 and farm 2 , respectively. ${ }^{10}$ The equi-

${ }^{10}$ Given that the entire cultivated area of land receiving the SPS must respect the cross-compliance regulations irrespective of whether all or part of the SPS entitlements are activated and irrespective of whether all or part of the land is used for the activation of entitlements (EUR-Lex 2003), cross-compliance costs, $c$, are linked to land, not to entitlements. As a result cross-compliance costs result in a downward shift of land demand functions. 


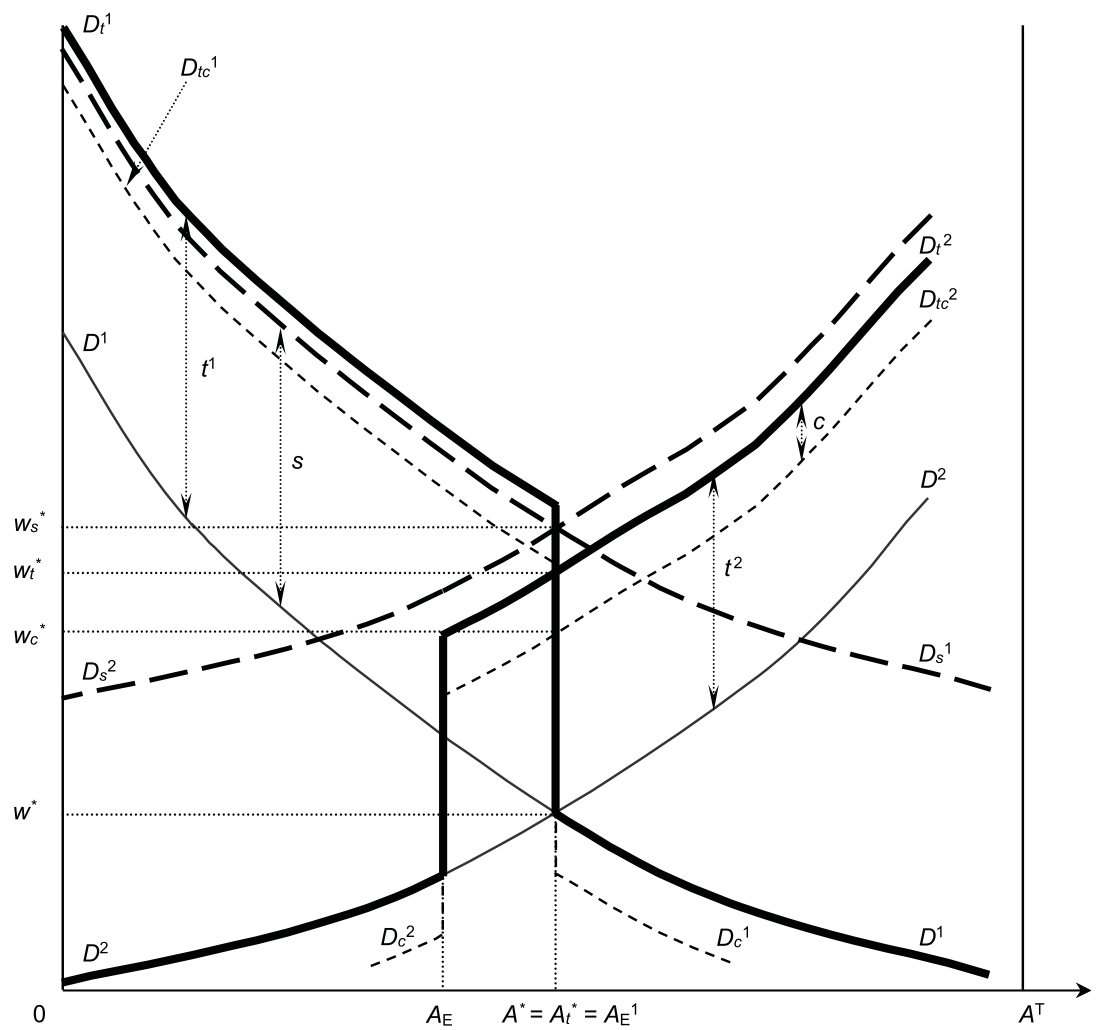

FIGURE 3

The Effect of the Single Payment Scheme and Coupled Area Payments

librium shifts from $\left(A_{t}^{*} w_{t}^{*}\right)$ to $\left(A_{t}^{*} w_{c}^{*}\right)$. Overall, the cross-compliance costs reduce the land rental price, implying that the SPS capitalization level is also lower (by $w_{t}^{*}-w_{c}^{*}$ ) relative to a situation without any cross-compliance costs, $w_{c}^{*}-w^{*}<w_{t}^{*}-w^{*}$.

Deficit entitlements are illustrated in Figure 1. Land demands with no cross-compliance costs are $D_{t}^{1} D^{1}$ and $D^{2} D_{t}^{2}$, for farm 1 and farm 2, respectively, and the land market equilibrium is at $\left(A^{*}, w^{*}\right)$, which is the same as without the SPS. The cross-compliance costs, $c$, shift the land demands of farm 1 and farm 2 to $D_{t c}^{1} D_{c}^{1}$ and $D_{c}^{2} D_{t c}^{2}$, respectively, and land rent drops from $w^{*}$ to $w_{c}^{*}$, relative to zero cross-compliance costs and deficit entitlements, and relative to a situation without the SPS. Hence, cross-compliance costs lead to negative capitalization of the SPS.

\section{Region-Specific Factors}

Further important factors that impact the actual SPS capitalization include various rigidities and region-specific aspects, such as credit market imperfections, social capital, and formal and informal land market institutions (Patterson, Hanson, and Robison 1998; Robison, Myers, and Siles 2002; Rainey et al. 2005; Siles et al. 2000; Tsoodle, Golden, and Featherstone 2006; Ciaian, Kancs, and Swinnen 2010). These factors may play a prominent role in determining the functioning of rental markets, as a result of which competitive pressures might be distorted or/and might not take full and immediate effect in such a setting (Gardner 2002). Moreover, regional variation in formal and informal land market institutions may lead to rental rates in differ- 
ent regions responding differently to the SPS. The exact impact depends on particularities of the formal/informal land market institutions and market imperfections, and on how they interact with land markets in general and with the SPS in particular. For example, studies for the United States show that social capital is a pivotal factor for the rural land market, influencing the type of transactions (e.g., Patterson, Hanson, and Robison 1998; Rainey et al. 2005), the price of the land (Robison, Myers, and Siles 2002), and the partners involved in the transaction (Siles et al. 2000). In many regions land transactions depend on the relationship between the parties (e.g., between landlord and tenants) involved and occur mainly between relatives or neighbors (Patterson, Hanson, and Robison 1998; Siles et al. 2000). According to estimates from the literature, this group may receive a rebate on the land price ranging from $10 \%$ (Robison, Myers, and Siles 2002) to $43 \%$ (Tsoodle, Golden, and Featherstone 2006), compared to competitive markets. According to Tsoodle, Golden, and Featherstone (2006), the influence of social capital has increased over recent years.

A key implication of these considerations for our analysis may be a more sluggish adjustment of land rents to the SPS. In addition, land rental prices may be more determined by the regional factors rather than by aggregate and/or external drivers. Furthermore, either rental market arrangements, which involve rental price controls (minimum or maximum prices) ${ }^{11}$ or formal and/or informal provisions on the duration of rental contracts ${ }^{12}$ (Ciaian, Kancs, and Swinnen 2010), may also lower the capitalization rates compared to prefect land markets.

\footnotetext{
${ }^{11}$ Land market regulations in the European Union vary strongly among member states. Of particular importance for the SPS capitalization is the maximum price intervention (Ciaian, Kancs, and Swinnen 2010).

12 According to Ciaian, Kancs, and Swinnen (2010), the key determinants of rental contract durations in the European Union are social norms (e.g., in Greece), governmental regulations (e.g., there is a minimum of 9 years in Belgium and France, 6 years in the Netherlands and 5 in Spain), and market institutions (e.g., Germany, Italy, Sweden). Moreover, in several countries (e.g., France) even the renewal of rental contracts is regulated.
}

With regulated land prices, long-term rental contracts, and informal relationships, one may not observe full capitalization of subsidies into land values in the short run. This effect is illustrated in Figure 2, where the equilibrium rent with the SPS (with entitlements $t^{1}$ and $t^{2}$ ) is $w_{t}^{*}$. If the rental price cannot adjust, for example, due to land market rigidities, then the actual rent that farms pay will be lower. In Figure 2 the actual rent will lie between $w_{t}^{*}$ and $w^{*}$, depending on the rigidity of land markets. This implies that the SPS capitalization rate will be lower with market rigidities than without, at least in the short run (i.e., it will be lower than $w_{t}^{*}-w^{*}$ ). However, in the long run, competitive pressures will tend to push adjustment of rents upward to $w_{t}^{*}$ with the renewal of rental contracts.

On the one hand, according to Ciaian and Swinnen (2009), subsidies may be capitalized at a higher rate than in a perfectly competitive market, if farmers are credit constrained. Subsidies may be substituted for missing finance, if farms are credit constrained, leading to higher input use and, hence, higher land productivity and enhanced SPS capitalization into land rents. In our model, the credit constraint effect is reflected in an upward shift in land demands. To simplify the explanation, in Figure 2 we assume that only farm 2 is credit constrained. Farm 1 is assumed not to be credit constrained, hence its land demand is not affected. The SPS with surplus entitlements has two effects on land rents in the presence of credit market imperfections: one direct and one indirect. The direct effect of the SPS is shown in the previous section in the absence of credit market imperfections and is equal to a rental price increase of $w_{t}^{*}-w^{*}$. The indirect effect results from the relaxed credit constraint of farm 2 , which due to the SPS allows the financing of higher input use and/or improvement of its technology. This increases the productivity of the land, which further increases the land demand of farm 2, resulting in higher rent, which reinforces the direct effect. The indirect credit constraint effect results in a shift in land demands from $D^{2} D_{t}^{2}$ to $D_{c c}^{2} D_{t c c}^{2}$ (dotted lines), for farm 2 . The new equilibrium is at $\left(A_{t}^{*} w_{t c c}^{*}\right)$. Compared to perfect credit markets, the SPS cap- 
italization into land rents has increased by $w_{t c c}^{*}-w_{t}^{*}$. The credit constraint effect depends on the size of the credit constraint. The more credit constrained farms are, the larger the productivity effect, and hence the higher the capitalization of the SPS. ${ }^{13}$

\section{General Equilibrium Effects}

Another important theoretical result is that in a given region, rents of all farms (including those that do not receive the SPS) are affected by the SPS (general equilibrium effect). The SPS capitalization is a result of competitive pressures among farms, where the land market equilibrium is reached by adjustment in land use and land rental price. Land use adjustment to the SPS is a farm-specific effect, reflecting variation in farm productivity (land demand elasticity) and the SPS entitlement allocation across farms. Land rents adjust equally to all farms in absolute terms, and the size depends on the SPS impact on marginal returns to land. For example, we have shown that under the surplus entitlements $t^{1}$ and $t^{2}$, the equilibrium land rent shifts from $w^{*}$ to $w_{t}^{*}$ (Figure 2). The land rent rises by the same amount $\left(w_{t}^{*}-w^{*}\right)$ for both farms, although the SPS value varies between farms, $t_{1} \neq t_{2}$.

\section{Differences in Capitalization between the SPS and the Previous CAP Subsidy System}

Prior to the introduction of the SPS in 2005/2006, E.U. farms received coupled subsidies. To compare the impact of the SPS with the previous subsidy system, we consider coupled area payments, which represented around $70 \%$ of all direct payments before the introduction of the SPS in the European Union. Area payments include, for example, payments for cereals, oilseeds and protein crops, rice, set-aside payments, and so forth. In general, they are land-based subsidies linked to the cultivation of certain crops (Dewbre, Anton, and Thompson 2001; Kilian et al. 2012). The value of area-based direct payment does not depend on the production level, but on the

\footnotetext{
${ }^{13}$ Even if the SPS does not affect land rents directly, for example, with deficit entitlements, its interaction with credit markets may lead to higher land rents.
}

area cultivated with the eligible crops and, hence, can be modeled as area subsidy, $s$. There are no entitlements associated with this subsidy scheme, and all farms receive the same value of subsidy. Given that there are no entitlements associated with area paymentsall farms receive the same value of the subsidy and all eligible land can benefit from themtheir impact on land rents is similar to the case of the region's SPS model with surplus entitlements. This implies that, for an equivalent value of area payment, the capitalization rate of area payment is equal to or higher than the capitalization rate of the SPS (Courleux et al. 2008; Kilian et al. 2012). In Figure 3 we illustrate the difference in capitalization rates between the two subsidy systems for surplus entitlements. As shown above, the land market equilibrium with entitlements $t^{1}$ and $t^{2}$ is $\left(A_{t}^{*}, w_{t}^{*}\right)$, implying that the capitalization of the SPS is equal to $w_{t}^{*}-w^{*}$. With an equivalent value of area payment, $s,{ }^{14}$ land demands of farms 1 and 2 are $D_{s}^{1}$ and $D_{s}^{2}$, respectively. The land market equilibrium shifts to $\left(A_{t}^{*}\right.$, $\left.w_{s}^{*}\right)$, implying that the full value of payment, $s$, is reflected in higher rents: $w_{s}^{*}-w^{*}=s$. Area payments result in higher capitalization than the SPS, $w_{s}^{*}-w^{*}>w_{t}^{*}-w^{*}$, and this difference increases in the variation of the face value of entitlements (i.e., under historical and hybrid SPS models). In the case of deficit entitlements, we have shown that the capitalization of the SPS is zero, implying that in this case, area payments also result in higher capitalization. Only with an equal face value of entitlements across farms (i.e., regional model) and surplus entitlements may the SPS result in the same capitalization level as the coupled area payment, as both lead to full capitalization. However, the regional model is not implemented by any of the studied member states.

These results imply that the CAP shift from coupled area payments to the SPS (as observed in empirical analysis, as discussed in a later section) will result in a decapitalization of the previous subsidy system, if indeed in

\footnotetext{
14 The equivalent value in terms of the same value of weighted average of SPS, that is, $s=\left[t^{1} A_{t}^{*}+t^{2}\left(A^{\mathrm{T}}-\right.\right.$ $\left.\left.A_{t}^{*}\right)\right] / A^{\mathrm{T}}$.
} 
reality the payments are incorporated in higher land values.

\section{ECONOMETRIC APPROACH}

\section{Estimation Issues}

The empirical estimation of the SPS capitalization is complex due to a number of estimation issues: selection bias, simultaneity bias, and general equilibrium effects. The theoretical results suggest that the rental price adjustments are determined by the overall marginal change, but not by farm-specific marginal changes in subsidies, implying that the farmland rental prices respond to policy changes at the same rate for all farms in a given region (general equilibrium effects) (Courleux et al. 2008; Kilian and Salhofer 2008; Ciaian, Kancs, and Swinnen 2008, 2010). Even those farms that did not receive the SPS may face upward adjustments in the farmland rental price.

The simultaneity between the SPS and land rents may cause an endogeneity issue. The SPS is not assigned randomly to farms but is endogenous, because it depends on regionand farm-specific productivity levels. Farms located in regions that are more productive received higher coupled subsidies than farms located in less productive regions. The allocation of the (decoupled) SPS is based on the values of coupled subsidies in the past. Under the historical model, the value of the SPS was set to the value of the coupled animal and crop subsidies that farms received in 2000-2002. Under the hybrid model, the SPS consists of a historical component (as in the historical model) and a regional component, which is positively correlated with regional productivities. This implies that regions that are more productive receive a higher SPS per hectare and, at the same time, are also likely to have higher rental prices. Given that the SPS and the land rental price simultaneously determine each other, in standard regressions the positive relationship between the SPS and the rental price would yield biased estimates.

The estimation of the SPS may suffer from selection bias, as farms' past production structure determined the level of coupled subsidies in the past and, hence, determines the current
SPS level. ${ }^{15}$ Farms that produced more supported commodities receive a higher value of the SPS per hectare, whereas farms that produced less supported commodities received a lower value of the SPS per hectare. Given that the choice of production structure was not random but dependent on farm characteristics (e.g., productivity, managerial skills), indirectly, farms may have selected themselves into a given level of the SPS intensity (selfselection bias). Another important source of selection bias is nonrandomness of nonparticipation in the SPS. It can be shown that if background characteristics (covariate averages) of farms that received the SPS (independent of the level of the SPS intensity) are very different compared to the control group, then using the traditional regression methods (e.g., a common effect model) for estimating the average treatment effects (ATE) of the SPS would yield biased results. For example, in a common effect model $(Y=a X+b t+v)$, where the effects of the intervention are estimated via coefficient $b$ (constant across $X$ ), bias for the ATE parameter $\left(E\left(Y_{1}-Y_{0}\right) \mid X\right)$ arises from the fact that the error term does not have conditional mean zero (Todd 2008).

The standard estimation approaches can only partially address the econometric issues identified above. For example, the endogeneity issue can be reduced by using instrumental variables (IV) estimators or the dynamic panel data approach (e.g., Kilian et al. 2012). However, the results using these estimators are susceptible to identification of appropriate instruments and dynamic model specification, respectively. The selection bias can be tackled by employing the Heckman two-step procedure. However, it imposes a nontrivial structure on the estimable model. In addition, because of insufficient variation in changes of the rental rates among farms, the traditional estimation methods are not able to capture the general equilibrium effect. Only part of the marginal effects (marginal capitalization), which differs from the general equilibrium effect and is farm-specific, can be identified. For this reason, the SPS effect

\footnotetext{
15 The production structure in the reference period codetermined the value of the SPS in both hybrid and historical models.
} 
will be underestimated in standard regression analysis.

\section{Addressing Estimation Issues with the GPS Estimator $^{16}$}

In order to address the above estimation issues, in the present study we employ the GPS matching estimator of Hirano and Imbens (2004). The GPS is particularly well suited in situations where the probability of receiving a given level (intensity) of support depends on the distribution of farm- and region-specific characteristics. As noted above, this is the case of the SPS, which is endogenous with respect to farm productivity, past coupled subsidies, farm characteristics, and regional characteristics, implying that some farms are more likely to receive a higher level of the SPS than others are. In the GPS, this endogeneity problem can be addressed by including past subsidies as well as output/productivity-related variables as additional covariates in the estimation approach (Section V).

Second, the GPS allows us to identify the general equilibrium effects of the SPS on land rents (i.e., including the level of rental prices of farms that were not directly supported). In order to estimate the SPS capitalization for different SPS intensity levels (and to control for the general equilibrium effect) (Section III), we divide the whole sample into several subsamples according to the SPS intensity levels.

Third, given that the SPS is a continuous variable, application of a binary propensity score matching estimator would be inefficient from the data use perspective. The SPS embraces almost all farms, and information about nonparticipants is scarce, implying that the identification of the capitalization rate would be problematic, because the control farms with zero support are rather few relative to the supported farms. ${ }^{17}$

\footnotetext{
${ }^{16}$ For a technical description of the GPS approach see the Appendix.

17 The SPS had been extended to most farms covering the entire territory of member states implementing SPS; that is, almost all farms received support, yet at various intensities.
}

Finally, in the context of the present study, an essential advantage of the GPS is that it eliminates (or at least substantially reduces) selection bias and allows us to estimate not only the average capitalization rate, but also capitalization rates for different SPS levels. Specifically, given the information about policy support intensity, it permits the estimation of average and marginal outcomes that correspond to each specific value (level) of support intensity. The latter property has very important policy implications, as it allows the effectiveness of the SPS to be assessed at various intensity levels. Such disaggregated results cannot be obtained by employing the traditional regression techniques or the binary propensity score matching methodology, regression discontinuity design, and so on, unless an almost perfect database is available for a large number of farms receiving the SPS at each possible intensity level, as well as for appropriate control groups. Clearly, this situation is not the case in the European Union.

\section{EMPIRICAL ANALYSIS}

\section{Data Sources and Variable Selection}

The main source of the data we employ in the empirical analysis is the Farm Accountancy Data Network (FADN); this data is compiled and maintained by the European Commission. The FADN is a European system of farm surveys that take place every year and collect structural and accountancy information on E.U. farms, such as farm structure and yield, output, inputs, costs, subsidies and taxes, income, and financial indicators. The FADN data is unique in the sense that it is the only source of harmonized (the bookkeeping principles are the same across all E.U. member states) and representative farm-level microeconomic data for the whole European Union. Farms are selected to take part in the survey based on stratified sampling frames established for each E.U. region.

Before cleaning and censoring the data, the balanced panel contained 19,000 farms covering four years (2004-2007) and the 15 member states in the EU-15. The choice of the period 2004-2007 was determined by the availability of data and by the attempt to cover 
the period before (i.e., 2004) and after (i.e., 2007) the introduction of the SPS. We have excluded the new member states from the sample (which joined the European Union in 2004 and 2007) because they implemented a different area payment system. Furthermore, we excluded all those farms that received SPS payments higher than $€ 10,000 /$ ha and paid more than $€ 3,000 /$ ha for land rent. ${ }^{18}$ The above data cleaning resulted in the retention of 16,428 farm observations, which represent the full sample in our estimations.

The dependent variable-difference in the farmland rental rate paid by each farm between 2004 and 2007-is constructed from the FADN data. ${ }^{19}$ Taking the difference between the land rent of farm $i$ in 2004 (prior to the SPS introduction) and 2007 (after a full implementation of the SPS) reflects the rental price change over a three-year period after the SPS introduction. Differentiating the series allows us to eliminate the unobservable regional farm-specific fixed effects and thus to reduce the region-dependent endogenous component from the rental values and farm-level covariates, which is likely correlated with the SPS value. Similarly, the SPS variable, $T$, is constructed from the FADN data. ${ }^{20}$

The selection of farm-level covariates is based on the condition that they simultaneously affect both the outcome (land rental price) and the intensity of the received SPS level. As discussed above, both farm productivity and the actual realized income signifi-

\footnotetext{
18 The rental costs in the FADN data include not only farmland rents, but also rents for buildings and other rental charges. For this reason, we attempted to correct this data problem by excluding from the sample farms with rents higher than $€ 3,000 /$ ha, because high-value rents likely represent rental for buildings. The magnitude of the estimated effects is of the same range also without censoring the sam-

19 The FADN data does not report the rental rate for farmland directly. However, it reports the total amount of rent paid for the rented land (SE375), and the total rented area under a tenancy agreement for a period of at least one year (SE030). By dividing the total rent paid by the hectares rented we construct the per hectare rental rate for each farm and each year.

${ }^{20}$ Every agricultural farm in the FADN sample reports the total subsidies received, as well as the amount of specific subsidy type. Per hectare, payments of the SPS are obtained by dividing the total SPS amount obtained in 2007 by the total utilized agricultural area (UAA).
} ple. cantly affect farms' willingness to pay for land rent. In order to control for simultaneity bias (reverse causality), we included two farm-level covariates: the total output per family labor, $X_{1}$, and the gross farm income per family labor, $X_{2}$. Note that these variables also implicitly account for cross-compliance restrictions. Although farmers do not report the cross-compliance costs separately, as their direct measurement is not possible, these costs are included indirectly in farm expenses and production. They influence farm activities (including production) (e.g., cross-compliance costs related to environmental requirements are the sum of the input use effect, such as fertilizers, and production effect) both directly and indirectly.

In addition to farm productivity and income, the previous literature (Lence and Mishra 2003; Patton et al. 2008; Kirwan 2009; Ciaian, Kancs, and Swinnen 2010; Ciaian and Kancs 2012) also identifies farm size and land supply as important determinants for explaining the variation in farm-level rental prices. In order to control for farm-scale effects and possible changes in land supply potentially affecting rural land markets, we included the total utilized agricultural area (UAA) area per family labor, $X_{3}$, and the economic size (measured in European size units on the basis of the European Community typology) per family labor, $X_{4}$.

Another set of important covariates selected in the empirical analysis (expected to determine both agricultural land rental price as well as the intensity level of the SPS) comprises proxies describing (1) a farm's potential to invest/grow, (2) a farm's access to credit, (3) the role of received subsidies in increasing a farm's capacities, and (4) the importance of policy return relative to the market return. The respective covariates we constructed for capturing these effects are the total liabilities per family labor, $X_{5}$, the ratio of total subsidies (excluding investment subsidies) to the gross farm income, $X_{6}$, the ratio of subsidies on investment to net investment, $X_{7}$, and the ratio of coupled subsidies to gross investment, $X_{8}$.

The final group of covariates suggested by theoretical studies contains variables capturing the potential impact of entitlements (Section III), that is, land entitlements per family 
labor, $X_{9}$. Also, given that the rental price may change with the share of rented land (e.g., due to differences in incentives with respect to own and rented land, reflecting the importance of regional land structure, or due to change in rental land supply), we include a ratio of rented land to UAA covariate, $X_{10}$.

All farm-level covariates are constructed from the FADN data and, with the exception of the number of land entitlements per family labor, $X_{9}$ (which relates to the year 2007), ${ }^{21}$ they all refer to the year 2004 (i.e., prior to the introduction of the SPS) (see the Appendix for a more detailed description).

In order to address the issue of regional heterogeneity and specificities of land markets (Section 3), we created two subsamples of highly different countries and introduced a set of control variables. To capture empirically the variation in the SPS implementation (Section 3), the first subsample includes countries that implement the hybrid SPS model (hereafter referred to as "hybrid").22 The second subsample covers countries that implement fully decoupled direct payments (hereafter referred to as "decoupling"). ${ }^{23}$ The difference between the results based on the full sample and the two subsamples will also reflect (besides the impact in variation of the SPS model and decoupling) the effect of unobservable dissimilarities in regional land market settings, the functioning of land markets, and regional structures in those countries, which were left from a subsample analysis. Comparisons of the results based on the full sample and the two subsamples are, therefore, also expected to reflect the specificity of land markets in the excluded countries, namely, France, Spain, Italy, Greece, and so forth, and differences between land markets in Scandinavia (i.e., Finland, Sweden, and Denmark).

In order to account for a possible endogeneity of the total land supply, ${ }^{24}$ we use a ho-

\footnotetext{
${ }^{21}$ Land entitlements were only introduced in 2005, simultaneously with SPS payments.

${ }^{22}$ Denmark, Finland, Germany, Luxemburg, Sweden, England, Northern Ireland.

${ }^{23}$ Germany, Luxemburg, United Kingdom.

24 Studies have shown that land supply elasticity may affect the actual capitalization of the SPS. In the case when land rents are affected by the SPS (e.g., surplus entitlements and cross-compliance costs), the capitalization decreases in
}

mogenous sample of farms (panel data) with the selection of control variables reflecting the impact of possible changes in land supply at farm level, that is, change in total area and land rented area. By including these covariates (before and after receiving the SPS), we attempt to control for possible changes in endogenous land supply, which might have occurred in all farms in our sample.

\section{Empirical Results}

We estimate the dose (SPS intensity) response (change in farmland rental price) function using parameter estimates of equation [A10] (see Appendix Tables A1-A8). The estimation results are reported in Table 1 and Figure 4 for the full sample and for the two subsamples. The average dose-response function (columns 2-4 in Table 1) shows how land rental price changes (difference between 2004 and 2007) respond to different intensity levels of the SPS per hectare (column 1). From the average dose-response function we calculate the average (columns 5-7) and marginal (column 8-10) SPS capitalization rates.

The results reported in Table 1 suggest that part of the SPS is capitalized into land rents, and that the capitalization rate of the SPS is different for different levels of the SPS per hectare. For the full sample, the marginal capitalization rate varies between $-43 \%$ and $94 \%$, whereas the average capitalization rate varies between $3 \%$ and $94 \%$ and is negatively correlated with the support level. Farms possessing low-value SPS entitlements channel a larger share of the SPS to landowners through higher land rents than other farms. Using information about the distribution of UAA (number of farms), our results suggest that in $2007^{25}$

\footnotetext{
land supply elasticity. This is because land markets may respond to the SPS by increasing/decreasing land supply (Courleux et al. 2008). However, this effect is expected to be rather insignificant due to the fact that the land supply elasticity is usually found to be rather low, mostly due to natural constraints. For example, based on an extensive literature review, Salhofer (2001) concludes that a plausible range of land supply elasticity for the European Union is between 0.1 and 0.4 .

25 To calculate the distribution of farms we use farmlevel FADN data for 2007 weighed by their share in the total population.
} 


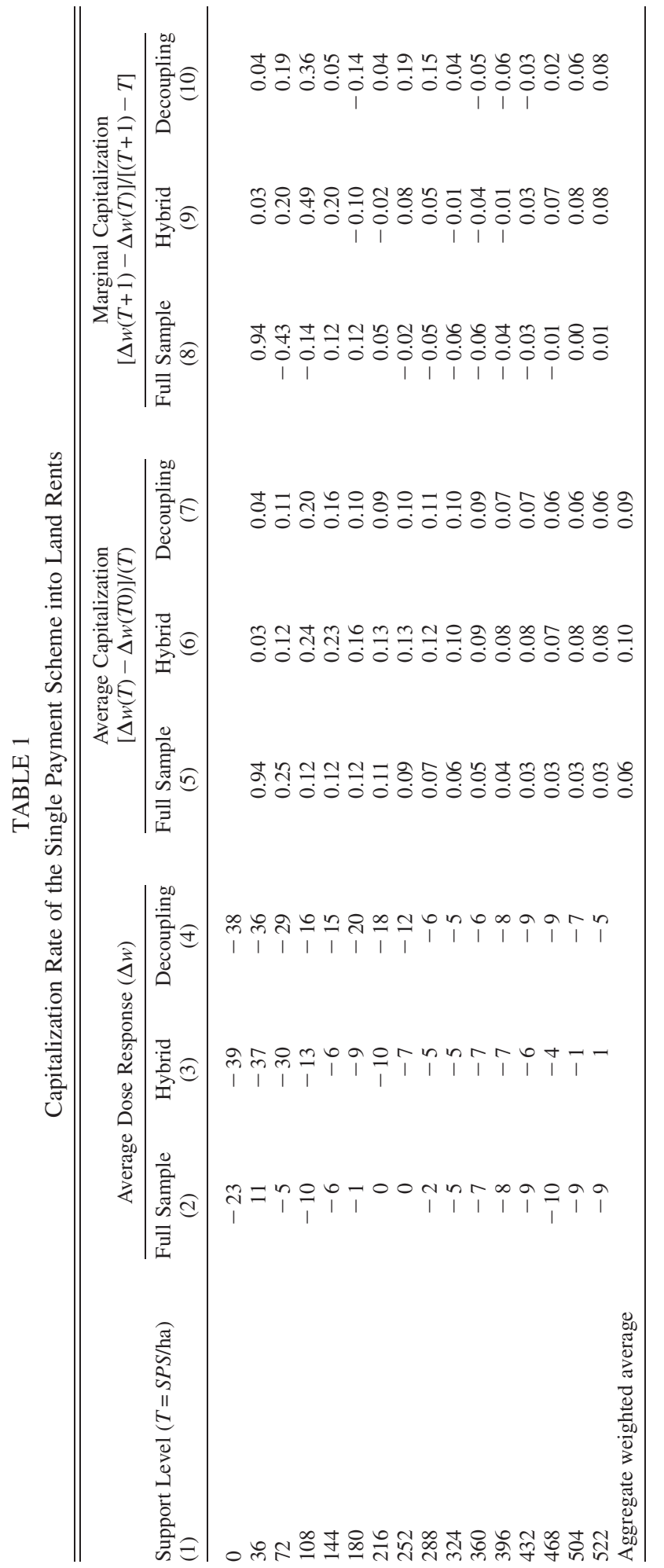




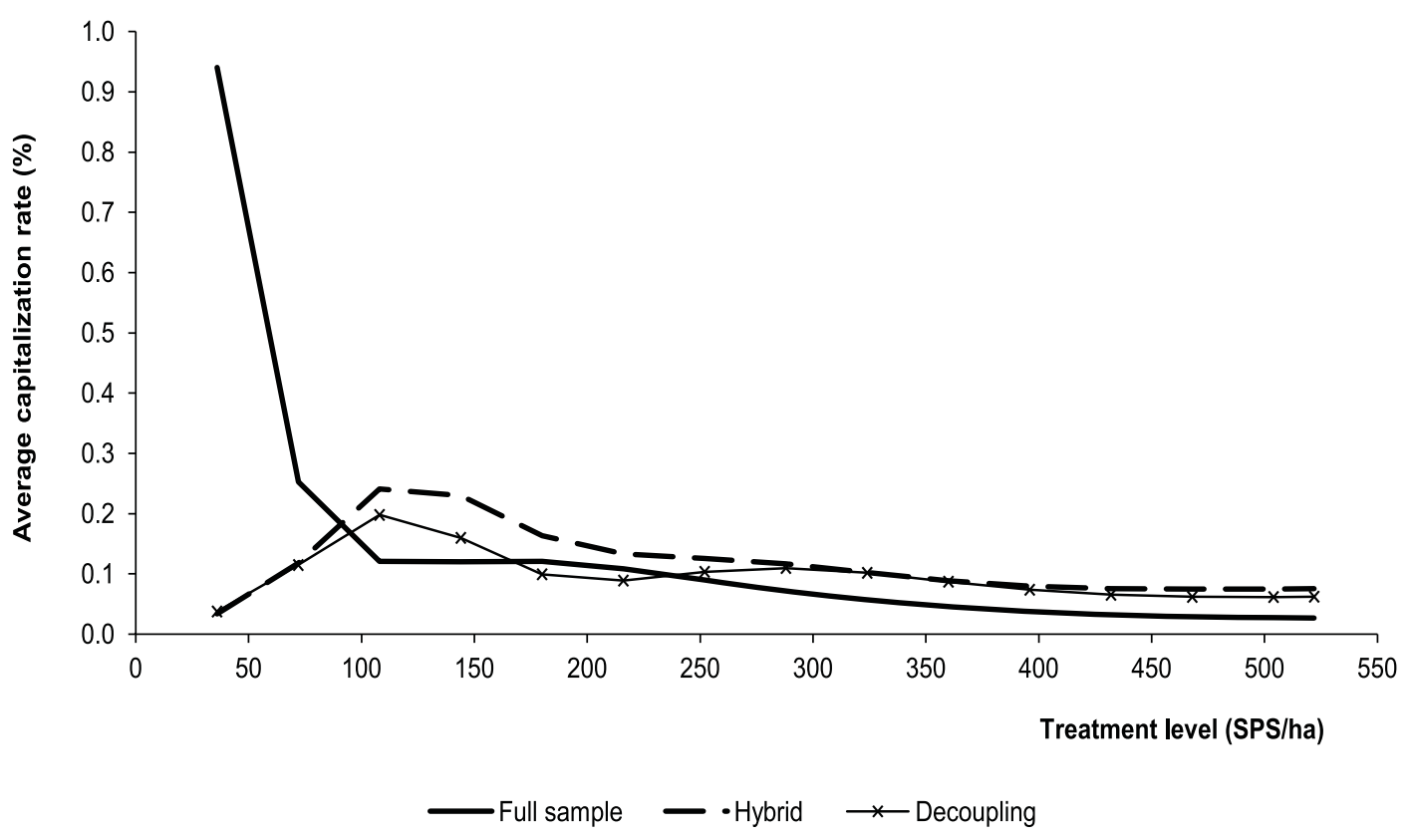

FIGURE 4

Average Capitalization Rate of the Single Payment Scheme for Different Support Levels

up to $50 \%(86 \%)$ of area (farms) in the EU-15 had an average capitalization rate of $10 \%$ or lower, whereas the rest of the area (farms) had a higher capitalization rate. These results are in line with the theoretical expectations. Given that the rental price change due to the SPS is region specific and the same for every farm before and after its introduction (general equilibrium effect), the capitalization rate is higher for farms possessing a lower amount of the SPS. In addition, the variation in the capitalization rate (given that the SPS is correlated with regional productivities) could also be due to regional segmentation of land markets and strong importance of local factors determining price formation (e.g., social and cultural norms and institutions). The variation in these factors may have resulted in differentiated responses of land rents to the SPS across regions (Siles et al. 2000; Rainey et al. 2005; Tsoodle, Golden, and Featherstone 2006).

The results for countries with the hybrid model (column 6 in Table 1) indicate a higher average capitalization rate for different SPS intensities than for the full sample (column 5). This is consistent with the theoretical analysis, which shows that the capitalization rate of the hybrid model should be higher than that of the historical model, as capitalization decreases with the variance of the support. The hybrid model reduces the variation in the level of the SPS per hectare among farms, implying that in equilibrium the marginal effect of the SPS on land rents is larger under this model compared to the historical model. ${ }^{26}$ An exception is the SPS lower than €70/ha (Table 1). This could be explained by the fact that, under the hybrid model, the SPS variation is reduced and thus there are fewer observations with low support level. As a result, the estimates may be less precise for low SPS values in the hybrid subsample. The higher capitalization for the hybrid model may also reflect differences in regional variations in land market institutions. Countries included in the hybrid subsample tend to have more flexible land markets compared to the average of the full sample, implying a stronger land market re-

\footnotetext{
${ }^{26}$ This is also true for marginal capitalization rates for most support intensities (column 9 versus column 8).
} 
sponse to the SPS (Ciaian, Kancs, and Swinnen 2010). However, in order to provide more robust results, more detailed regional data on land market institutions is required.

For the subsample of countries with full decoupling (column 7 in Table 1), the average capitalization rate is between that of the full sample and the hybrid subsample. The key difference between the full and the partial decoupling is that under the former more direct payments are allocated to the SPS, implying a higher level of support intensity. As shown in theoretical analysis, the SPS itself may lead to a positive impact on land rents. The actual impact depends on variation in support among farms. Given that the decoupling subsample includes both types of countries (those with the hybrid model and those with the historical model), the average capitalization rates in the decoupling subsample should be lower compared to the hybrid subsample but should be larger than in the full sample, which is consistent with the estimates reported in Table 1.

The results on the capitalization rates for different SPS levels reported in Table 1 are not directly comparable with those available in the literature because most studies have estimated the average capitalization rate using a standard regression approach and do not report estimates for different support intensities. Our results show that the aggregate capitalization rate, which is calculated as the weighted average of average capitalization rates, is relatively low, namely, $6 \%$ for the full sample (column 5 in Table 1). ${ }^{27}$ The corresponding values for the hybrid and the decoupling subsamples are 10\% and 9\%, respectively. Our estimates are lower than estimates on decoupled payments in the United States, according to which the capitalization rate of decoupled subsidies varies between $20 \%$ and 80\% (Goodwin, Mishra, and Ortalo-Magné 2003; Lence and Mishra 2003). The lower capitalization rate estimated for the European Union could be due to the rigidity of rental markets, which may be induced by formal and informal land market institutions and regulations. The rental market arrangements in the European Union may involve either rental

\footnotetext{
27 The total value of the SPS was used as weight.
}

price controls or provisions on the duration of rental contracts, in the presence of which land rents would not adjust instantly to market signals but would stay unchanged over time (Ciaian, Kancs, and Swinnen 2010). Given that (1) our estimates reflect rental price changes over a four-year period, (2) the duration of rental contracts in some cases is longer than five years, and (3) maximum rental price interventions are applied in several member states, our estimated capitalization rate may be understated. Yet, our results are in line with the theoretical expectations (see Section III), according to which the capitalization rate may be larger than zero.

However, we must also note that we were not able to fully account for regional heterogeneity in land market institutions, as consistent regional data are not available yet. The actual actions of farmers and landowners may also be influenced by the type and intensity of social relations between farmers and landowners, and by societal norms and the cultural context (Robison and Flora 2003). Interregional differences in social capital and informal institutions may cause differences in the capitalization rate. For example, in many southern E.U. regions, farmland transactions depend on the relationship between landlord and tenants and occur mainly between relatives or socially close neighbors, eventually resulting in lower land prices (Siles et al. 2000; Robison, Myers, and Siles 2002; Tsoodle, Golden, and Featherstone 2006). In our analysis, we were not able to account for all factors related to social capital and informal rural institutions, as reliable data to measure them are not available. Thus, this is another reason why our estimates may be understated.

From the average dose-response values, we calculated the general equilibrium effect of the SPS. The general equilibrium effect represents changes in the rental price due to the SPS, which was the same for all farms (including those not receiving SPS). We can identify the general equilibrium effect by estimating the SPS impact on land rents for farms with zero SPS value (capitalization rate at intensity level $T=0$ ). Although many farms do not receive the SPS,${ }^{28}$ they are affected by

\footnotetext{
${ }^{28}$ Farms with zero SPS represent $4 \%$ of total farms in
} 
the overall rental price adjustment to the SPS. According to theoretical considerations, the shift from the old system of coupled payments to a new policy of decoupled SPS should be negative if indeed they were capitalized into land rents (Section 3). Additionally the general equilibrium effects may reflect the impact of the cross-compliance. According to theoretical analysis, the cross-compliance costs reduce the SPS capitalization irrespective of whether land is used for entitlements activation or not (Section 3). The cross-compliance regulations are the same across the European Union and do not depend on the level of the SPS. The estimates reported in Table 1 (columns 2, 3, and 4), indicate that the rental prices decreased by $€ 23$, €39, and $€ 38 /$ ha for farms with zero SPS for the full sample, the hybrid, and fully decoupled subsamples, respectively. This represents $7 \%$ to $12 \%$ of the average SPS per hectare in the EU-15.29 These results suggest the importance of crosscompliance effect or/and an initial decapitalization of the previous subsidies due to the introduction of the SPS. Hence, our empirical results are in line with the theoretical hypothesis, which says that that cross-compliance may reduce rents and/or that a switch from coupled payment system to the SPS should result in lower rents for farms with zero SPS.

In general, our findings are in line with previous studies on decoupled subsidies, which find that decoupled subsidies affect rental prices. This can be explained by the fact that decoupled subsidies are often land based, conditioned on other policy measures, and interact with farm characteristics (e.g., farm credit constraint) (Goodwin, Mishra, and OrtaloMagné 2003; Lence and Mishra 2003; Roberts, Kirwan, and Hopkins 2003; Kirwan 2009; Ciaian and Kancs 2012; Barnard et al. 1997; Patton et al. 2008). Our estimates contrast somewhat with the estimates of Kilian et al. (2012), according to which the SPS increases the capitalization by an additional $15 \%$ to $19 \%$ above the previous coupled sub-

\footnotetext{
the full sample and $0.5 \%$ in the hybrid and the decoupling subsamples.

${ }^{29}$ In principle this figure (adjusted by the cross-compliance effect) should reflect the capitalization rate of previous coupled payments.
}

sidies. However, given that Kilian et al. (2012) use traditional estimation techniques (OLS and IV) and only one cross-section of data, they are not able to control for important econometric issues such as endogeneity, general equilibrium effects, and selection bias, implying that their estimates might be biased.

Based on the estimated SPS incidence for the full sample (column 5 in Table 1) and on farm-level FADN data on land renting and the SPS values for 2007, we have calculated the aggregate capitalization rate and nonfarming landowner gains from the SPS by farm size, by member state, and for the EU-15. We use the estimates from the previous section to calculate the capitalization rates by member state, as the estimation by member state was not feasible with the GPS approach due to insufficient number of available observations. The capitalization rate represents the SPS gain for all landowners (both farming and nonfarming), whereas nonfarming landowner gains represent policy benefits only for those landowners who are not involved in farming. The results reported in Table 2 show that the share of the SPS channeled either to farms or to nonfarming landowners was relatively low. On average, $7 \% 30$ of the total SPS (column 9) was channeled to landowners through higher rental prices in the EU-15. Nonfarming landowners gain only $4 \%$ of the SPS, because farmers in the EU-15 own a substantial share of land (69\% of UAA, column 5). The relatively small SPS leakage to landowners is because farms with a high-value SPS entitlement per hectare have lower capitalization intensity than those with a low-value SPS entitlement per hectare, implying that the former significantly offsets the latter when calculating the SPS-weighted average capitalization over all farms. However, due to the higher share of land renting (columns 10-12 and 1416), large farms lose a higher share of the SPS than small farms.

The largest leakages of the SPS to landowners $(18 \%)$ were found in Portugal, due to the relatively low SPS value per hectare, followed by Finland, Sweden, Spain, Austria,

\footnotetext{
${ }^{30}$ Note that the slight difference between this value and the aggregate capitalization rate reported in Table 1 is due to the difference in sample sizes.
} 


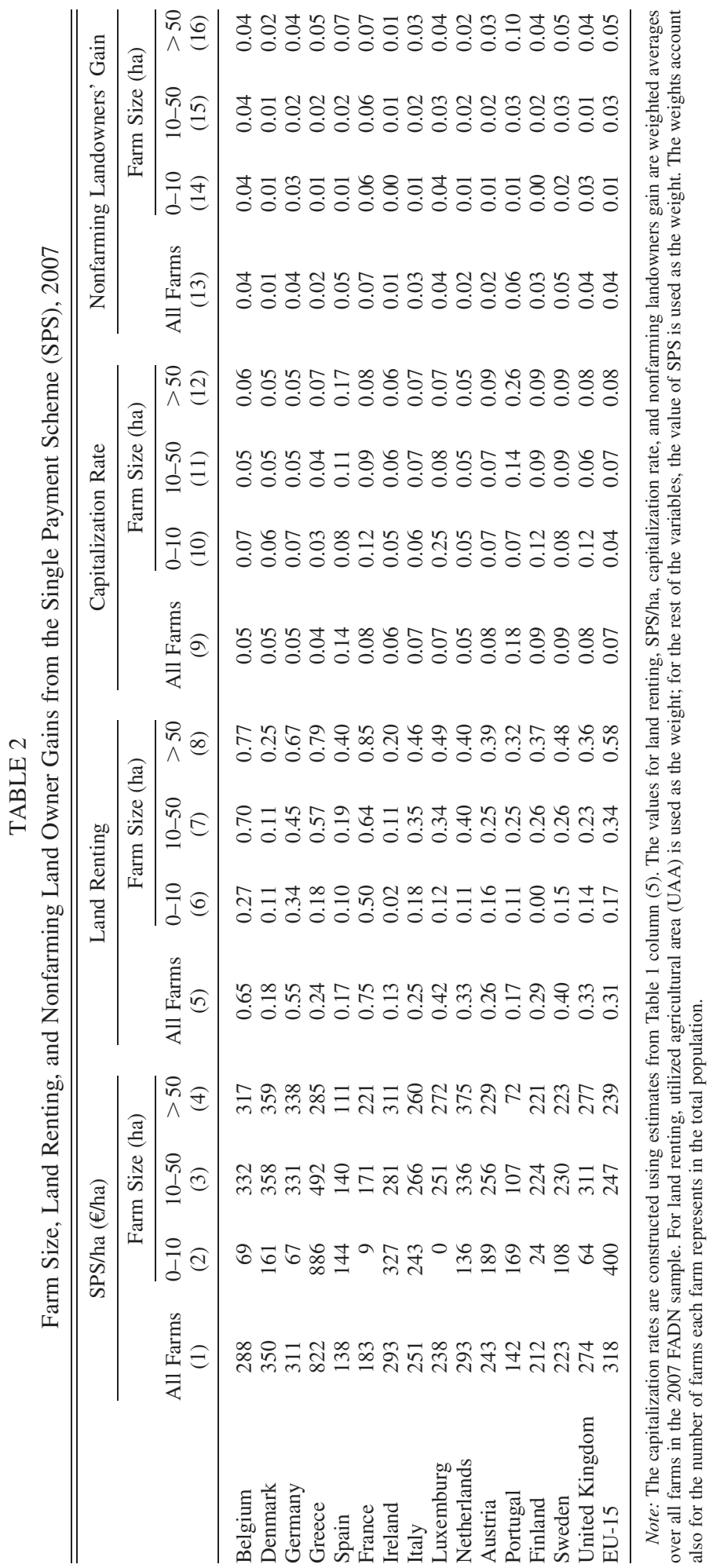


France, and United Kingdom, where around $8 \%$ to $9 \%$ of the SPS flows to landowners. In Greece the leakages were the smallest due to the relatively high SPS value per hectare: only $4 \%$ of the SPS is channeled to landowners (column 9). Furthermore, the results suggest that taken together, the EU-15 capitalization is greater for large farms than for small farms (columns 10-12). However, at country level the results are more diverse. In some countries large farms channel more (e.g., Austria, Greece, Spain, Portugal), whereas in some other countries small farms channel a larger share of the SPS to landowners (e.g., Finland, France, Luxemburg, United Kingdom). In other member states the differences between small and big farms are minor (e.g., Belgium, Denmark, the Netherlands, Ireland, Italy, Sweden).

Clearly, the main driver for the nonfarming landowner's gains from the SPS is the share of rented land in the overall UAA. Countries with a high share of rented land tend to channel a larger share of the SPS to nonfarming landowners (e.g., France) than countries with low farm rental (e.g., Denmark, Ireland) (column 13). At the same time, in most countries the leakage of the SPS to nonfarming landowners was positively correlated with farm size (columns 14-16) because land rental is more widespread in the former group of farms (columns 6-8).

\section{Policy Implications}

Our findings have important policy implications. First, our results are important in the context of the WTO trade liberalization agenda. Following the WTO agenda, many countries (including the European Union) decoupled their agricultural subsidies with the aim of reducing the distortionary impact on the world market (Meléndez-Ortíz, Bellmann, and Hepburn 2009). In the European Union the 2003 CAP reform replaced the previous subsidy system linked to the level of animal production and crop land use (so called coupled subsidies). Several studies, however, find that even decoupled subsidies may still affect farms' production decisions and factor allocation and thus may not be fully in line with the WTO requirements (Lagerkvist 2005; Ahearn, El-Osta, and Dewbre 2006; Goodwin and Mishra 2006; Vercammen 2007; Key and Roberts 2009; Whitaker 2009; Ciaian and Swinnen 2009; Bhaskar and Beghin 2010; Carpentier, Gohin, and Heinzel 2012). Our results confirm these findings: the decoupled SPS induces distortions in factor markets through altering farmers' land marginal decisions (reflected through their impact on land rental prices).

Second, a better understanding of the SPS capitalization into land rents, and hence the leakage of farm subsidies to landowners (in many cases nonfarmers), provides important insights to policy makers about the effectiveness and efficiency of the CAP subsidies. The SPS capitalization is of particular relevance in the context of the EU-15, where on average $31 \%$ of agricultural land is rented (the share of rented farmland varies between $13 \%$ in Ireland and $75 \%$ in France). Empirical knowledge about the SPS incidence provides policy makers with important information on how the benefits of a given agricultural policy are shared between farmers and factor owners.

Finally, given that large farms tend to rent more farmland than small farms, the SPS may have differentiated income effects across farms. This implies that the income effect of the SPS also differs considerably between farm types and E.U. countries.

\section{CONCLUSIONS}

This paper studies the capitalization of the SPS into land rents. First, we theoretically analyze how the SPS affects the land market and land rents. The theoretical analysis suggests that the capitalization may vary from a full to negative rate, and that it decreases with the variation in the entitlement value among farms. Furthermore, because of farm heterogeneity and because of various factors interacting with the SPS, the capitalization rate will be different for different levels of the SPS intensity.

In the empirical analysis, we use a unique farm-level panel data set for E.U. member states and employ the GPS matching approach for estimating the capitalization of the SPS. 
The application of the GPS matching estimator for the assessment of the impact of the SPS on the land rental price allows a less biased and more precise estimation of the average and marginal effects of the SPS, compared with traditional estimations based on the standard regression techniques or with the binary propensity score matching.

Our results suggest that, on average in the EU-15, $6 \%$ to $7 \%$ of the SPS is capitalized into land rents (varying from $4 \%$ in Greece to $18 \%$ in Portugal), implying that, in general, landowners do not absorb much of the SPS. However, there is a considerable variation in the capitalization rate for different SPS levels: low-value SPS is capitalized more than highvalue SPS. Farms with low-value entitlements channel a substantially higher share of the SPS to landowners than farms with high-value entitlements. The capitalization rate varies between $11 \%$ and $94 \%$ for the SPS smaller than $€ 200 /$ ha. For high-value SPS (i.e., SPS greater than $€ 200 /$ ha), the capitalization rate is considerably lower, between $3 \%$ and $11 \%$. Furthermore, our results indicate that the hybrid model and full decoupling of previous subsides lead to a higher capitalization rate, which is consistent with the theoretical hypothesis.

Our results suggest that implementation of the SPS is largely in line with the policy objective of improving income and the standards of living of the agricultural community. This is because the SPS capitalization rate into land rents and its leakage rate to nonfarming landowners are relatively low (although, in absolute terms, the value of the leakage to nonfarming landowners is not negligible). In 2011, the total value of the SPS represented around $€ 30.4$ billion in the EU-15 (EUR-Lex 2011). If we consider the $4 \%$ leakage rate of the SPS to nonfarming landowners (Table 2), around $€ 1.22$ billion was channeled outside the farming sector. However, the effectiveness of the SPS is highly heterogeneous and varies substantially depending on the applied intensity level and renting pattern. Farms owning low-value SPS have a higher leakage rate of subsidies to landowners than farms owning high-value SPS. Moreover, the leakage rate was much larger for big farms than for small farms due to differences in land renting patterns. Clearly, empirical knowledge of SPS incidence provides policy makers with information on how the benefits of a given agricultural policy are shared between farmers and the nonfarming community and thus help to better assess the effectiveness of such a policy.

Our results are consistent with the literature, emphasizing that even decoupled subsidies may distort agricultural markets and thus may not be fully in line with the WTO priorities to reduce policy distortions on world markets. According to our findings, the decoupled SPS induces distortions in input markets through altering farmers' land marginal decisions (reflected through their impact on land rental prices). However, the actual production effect caused by the induced land use changes cannot be derived from our results; this analysis is beyond the scope of this paper. Its effect is likely to be limited due to the low elasticity of land supply estimated in the literature for E.U. countries (Salhofer 2001). At the same time, our results lend support to the E.U. policy for the decoupling of CAP subsidies. Our findings indicate that the introduction of the SPS may have led to a decapitalization of coupled subsidies, implying that distortions in the land markets were actually reduced, if compared to the capitalization of the previous coupled subsidies.

Our results are subject to several limitations. The presence of long-term rental contracts implies that we may not have been able to fully capture long-term adjustments in land rents using data for only four years. Our estimates are also affected by regional heterogeneity, for example, differences in social capital and informal rural institutions, which we were not able to fully control for in our estimations. Additionally, covering the first implementation years of the SPS, when the familiarity with the new subsidy system may not have been fully realized by market agents, could have affected the actual capitalization rate of the SPS. These issues are a promising avenue for future research and should be addressed as soon as more data become available. 


\section{APPENDIX}

\section{GPS Approach}

In order to estimate the average capitalization rate (ACR) and the marginal capitalization rate (MCR) of the SPS, the GPS requires that for each observation $i$ we observe the support (SPS) intensity received, $T_{i}$, the outcome variable (land rent) corresponding to the received level of support, $Y_{i}\left(T_{i}\right)$, and a $p$-vector of covariates $\mathbf{X}_{i}$. The ACR and MCR can be derived from the average dose-response function (ADRF), $\mu(t)$, and the derivative dose-response function (DDRF), $v(t)$, respectively: ${ }^{31}$

$\mu(t)=E\left[Y_{i}(t)\right]$,

$\left.v(t)=\left[Y_{i}(t+1)-Y_{i} t\right)\right]$,

where $Y$ is the potential effect on land rental price, $t$ represents the potential SPS values, and $F$ is a continuous set of potential support values, where $t \in F$ and $T_{i} \in\left[t_{0}, t_{1}\right]$. For farm $i$ the corresponding set of potential outcomes are $Y_{i}(t)$, where $Y_{i}(t)$ is a unit-level dose-response function of outcomes that maps the particular potential support, $t$, to the potential outcome, $Y_{i}(t)$, (outcome function of the potential support intensity).

Using the estimated average dose-response function, $\mu(t)$, we can calculate the ACR and MCR of the SPS:

$A C R=[\mu(t)-\mu(0)] / t$,

$M C R=[\mu(t+1)]-\mu(t)] /[(t+1)-t]$,

where both ACR and MCR are evaluated at a representative point for each support interval, $t$.

31 The dose-response function measures the relationship between the exposure to the SPS as the cause and potential rental price outcomes as the effect. The ADRF captures the entire function of the average potential rental price outcomes, $Y_{i}(t)$, which gives the average potential outcome at every possible level (or dose) of the SPS, $t$. Given that the ADRF provides information about the estimated average rental price outcome corresponding to the specific level of the SPS, the potential outcome, which relates to zero support level, $t=0$, describes the magnitude of general equilibrium effects, that is, it shows the extent to which farms that have not received any SPS were affected by it. The general equilibrium effect represents the change in capitalization of previous coupled subsidies relative to the SPS, as we capture the periods before and after the implementation of the SPS (see Section V).
Empirical implementation of the GPS approach (Hirano and Imbens 2004; Bia and Mattei 2008) consists of three main steps.

The first step involves the estimation of the GPS as a conditional density of SPS support given the covariates. This step consists of several routines. Firstly, we assume that the support (or its transformation) has a normal distribution conditional on covariates. The estimation of parameters of the support function, $g$, (conditional distribution of support) is conducted using the maximum likelihood estimator.

$g\left(T_{i}\right) \mid \mathbf{X}_{i} \sim N\left\{h\left(\gamma, \mathbf{X}_{i}\right), \sigma^{2}\right\}$,

where $\mathbf{X}_{i}$ is an observed vector of presupport covariates for each unit $i$ in the sample, $g\left(T_{i}\right)$ is a given transformation of the support variable, and $h\left(\gamma, \mathbf{X}_{i}\right)$ is a function of covariates with linear and higher-order terms that depends on a vector of parameters $\gamma$.

Second, the validity of the assumed normal distribution is assessed using Kolomogorov-Smirnov, Shapiro-Francia, Shapiro-Wilk, or skewness and kurtosis tests for normality.

Third, the GPS, or $\hat{R}_{i}$, function is estimated. The $\hat{R}_{i}$ returns the conditional density of the actual support intensity given the observed covariates.

$\hat{R}_{i}=\frac{1}{\sqrt{2 \pi \sigma^{2}}} \exp \left[-\frac{1}{2 \hat{\sigma}^{2}}\left\{g\left(T_{i}\right)-h\left(\hat{\gamma}, \mathbf{X}_{i}\right)\right\}\right]$,

where $\hat{\gamma}$ and $\hat{\sigma}^{2}$ are the estimated parameters in equation [A5].

Finally, we test the balancing property of the estimated GPS function:

- We divide the set of support values (i.e., support intensity) into $k$ intervals.

- Within each support interval $k$, we calculate the median intensity and compute the GPS at this representative point.

- We subdivide the values of the GPS evaluated at the representative point of each support interval into $j$ blocks.

- For each block $j$ of the GPS scores and within each interval $k$ we calculate the mean difference of each covariate between units that belong to the support interval and units that belong to another support interval but are in the same GPS interval.

- Next we combine the differences in means calculated in the previous step, by using a weighted average with weights given by the number of observations in each GPS interval.

- For each computed difference we perform a $t$-test, which indicates whether the mean difference of each covariate between units that belong to the given support interval $k$ is statistically different 
from the mean difference of units that belong to another support interval but are from the same GPS block. If the mean differences for a given covariate are statistically significant this would imply that for this specific variable the estimated GPS was not able to completely eliminate a selection bias (although some reduction of bias could have been achieved).

The second step in the GPS approach involves the estimation of the SPS impact on land rental price using a flexible function (polynomial approximation) of $T_{i}$ and $R_{i}$ :

$Y_{i}=f\left(T_{i}, R_{i}\right)$.

Equation [A7] can be rewritten in terms of $\varphi\left\{E\left(Y_{i} \mid T_{i}, R_{i}\right\}=\hat{\psi}\left(T_{i}, R_{i} ; \alpha\right)\right.$, yielding

$$
\begin{aligned}
\psi_{i}\left(T_{i}, R_{i} ; \alpha\right)=\alpha_{0}+\alpha_{1} T_{i} & +\alpha_{2} T_{i}^{2}+\ldots \alpha_{4} R_{i} \\
& +\alpha_{5} R_{i}^{2}+\alpha_{6} R_{i}^{3}+\alpha_{7} T_{i} R_{i},
\end{aligned}
$$

where $\psi_{i}$ is farmland rental rate and $\boldsymbol{\alpha}$ is a vector of parameter estimates.

Estimating equation [A8] allows us to find the appropriate functional relationship between the impact indicator (land rental price) and the intensity of support, $T$, and the estimated values of GPS at the first stage, $R$, for each farm $i$, on the other. While $R$ controls for potential selection bias and endogeneity into support intensities, we anticipate that respective parameters $\left(\alpha_{4}\right.$ to $\left.\alpha_{6}\right)$ will be statistically significant.

The third and final step in the GPS involves estimation of the average potential outcome for each potential level of support $t$ and the entire dose-response function:

$$
\begin{aligned}
E\{\hat{Y}(t)\} & =\frac{1}{N} \sum_{i=1}^{N} \hat{\beta}\left\{t, \hat{r}\left(t, \mathbf{X}_{i}\right)\right\} \\
& =\frac{1}{N} \sum_{i=1}^{N} \varphi^{-1}\left[\hat{\psi}\left\{t, \hat{r}\left(t, \mathbf{X}_{i}\right) ; \hat{\boldsymbol{\alpha}}\right\}\right],
\end{aligned}
$$

where $\hat{\alpha}$ is the vector of the estimated parameters in equation [A8].

The average response at each $t$ is estimated as the average of the estimated conditional expectations $\hat{\beta}\left\{t, \hat{r}\left(t, \mathbf{X}_{i}\right)\right\}$ averaged over the distribution of the presupport covariates $\mathbf{X}_{i}$, that is, $\hat{\beta}\left\{t, \hat{r}\left(t, \mathbf{X}_{i}\right)\right\}=$ $\varphi^{-1}\left[\hat{\psi}\left\{t, \hat{r}\left(t, \mathbf{X}_{i}\right) ; \hat{\boldsymbol{\alpha}}\right\}\right]$, which equals the average value of the estimated regression function over the score function evaluated at the desired level of support. In order to obtain estimates of the entire doseresponse function, the estimation of the average potential outcome is repeated for each level of support. At the end, we estimate the rental price response for all levels of support intensity, $t$, which allows us to calculate the ACR and MCR (equations [A3] and [A4]).

\section{Description of Covariates}

Given that agricultural productivity is one of the key determinants of farmland rental rates, we include the variables total output per family labor $\left(X_{1}\right)$ and gross farm income per family labor $\left(X_{2}\right)$. The total output per family labor covariate is constructed by dividing the total of output of farm (SE131) by the total family labor (SE016). The gross farm income per family labor covariate is constructed from the FADN variable SE410 and represents farm income net of variable costs. The first variable is a proxy for productivity, whereas the latter one accounts for profitability.

To account for scale effects we consider variables UAA per family labor $\left(X_{3}\right)$ and economic size per family labor $\left(X_{4}\right)$. The total UAA per family labor covariate is constructed from the FADN variable total UAA of the holding (SE025), which we divide by total family labor (SE016). It consists of land in owner occupation, rented land, and land in share cropping. The economic size per family labor covariate is constructed by dividing the FADN variable SE005 (the economic size of holding expressed in European size units on the basis of the European Community typology) by the FADN variable SE016. In order to account for farm access to credit, in the estimation we also include the total liabilities per family labor covariate, $X_{5}$, (i.e., total liabilities, SE485, divided by family labor). Total liabilities include long-, medium-, and short-term loans. We construct a variable of the ratio of total subsidies (excluding investment) to gross farm income $\left(X_{6}\right)$ by dividing the FADN variable subsidies on current operations linked to production (not investments) (SE605) by the gross farm income (SE410). The ratio of subsidies on investment to net investment covariate $\left(X_{7}\right)$ is constructed by dividing subsidies on investments (SE406) by net investment on fixed assets (SE521). The ratio of coupled subsidies to gross investment covariate $\left(X_{8}\right)$ is constructed by dividing the sum of FADN variables SE610 (total subsidies on crops) and SE615 (total subsidies on livestock) by the FADN variable SE516 (gross investment on fixed assets $=$ purchases - sales of fixed assets + breeding livestock change of valuation). The land entitlements per family labor covariate $\left(X_{9}\right)$ is calculated by diving the FADN variable L470I (quantity of entitlements for payments under SPS) by the FADN variable SE016. Finally, we include the ratio of rented land to UAA covariate $\left(X_{10}\right)$. The variable is calculated by dividing rented UAA (SE030) by UAA (SE025). 


\section{Specification Tests}

The conditional distribution of support intensity (support function) given farm-specific covariates (equation [A5]) is estimated with the SPS intensity level, $T$, per farm as the dependent variable, and covariates, $X_{1}$ to $X_{10}$, as arguments. Since the empirical distribution of the SPS is highly skewed, it was transformed by taking logarithms, and the support function is estimated by applying the maximum likelihood estimator to the transformed log function. The estimation results are reported in Table A1 for the full sample and Table A5 for the two subsamples: the hybrid and the fully decoupled subsamples.

The results suggest that the conditional distribution of the SPS is clearly explained by the selected covariates. Most of the covariates (including the constant) exert a significant impact on support intensity at a significance level of $10 \%$, yet some differences in the significance of individual covariates are visible between the full sample and the two subsamples.

In order to assess the validity of the assumed normal distribution, we perform normality tests. The test results for the normality of disturbances (STATA skewness and kurtosis test for normality) confirm that after $\log$ transformation the assumption of normality is statistically satisfied at a 5\% significance level.

Given the farm-specific information, $T_{i}$, covariates, $\mathbf{X}_{i}$, and parameters estimated in the previous step, the value of the GPS, $R_{i}$, for farm $i$, is calculated (evaluated) as a conditional density of the actual support intensity given the observed covariates (see equation [A6]).

The applicability of the GPS in the estimation of the dose-response function depends on whether the included covariates are well balanced. Farms that received different SPS payments are not directly comparable because they may systematically differ in terms of observable characteristics, $\mathbf{X}_{i}$. The GPS eliminates (reduces) potential econometric problems and removes bias (e.g., selection bias) associated with differences in covariates by balancing the groups of farms. The GPS calculates a balancing score, which is a function of the observable covariates, $\mathbf{X}_{i}$, such that the conditional distribution of $\mathbf{X}_{i}$, given the balancing score, is the same for all farm groups, independent of the level of the treatment, SPS, intensity. Balancing property ensures that, once controlling for the observable characteristics of different groups of farms, at each value of the balancing score the distribution of covariates $\mathbf{X}_{i}$ is the same, independent of the treatment, SPS, intensity. Therefore, in the next step we investigate whether the underlying GPS specification is adequate, that is, whether it balances the covariates. In order to implement the balancing property tests, the range of support intensity is divided into four SPS intervals $(k=4), t_{1}$ to $t_{4}$ (see Table A3 for the full sample and Table A7 for two subsamples). The summary statistics of the GPS distribution calculated at mean points for each support interval is shown in Table A2 for the full sample and Table A6 for subsamples. The results demonstrate that, building on the conditional density of receiving the SPS and given the covariates, the GPS values calculated for all support intervals differ considerably, the lowest being in support group 1, that is, in a group where the obtained level of the SPS was less than $35 € /$ ha, and the highest in support group 2, that is, the SPS ranged between 35 and $900 € /$ ha. Furthermore, the values of the GPS evaluated at the representative point for each support interval (median) are subdivided into three intervals, which are defined by quintiles of the GPS.

Balancing tests using $t$-statistics are carried out to assess whether observations on farms with the same GPS score have the same distribution of observable covariates independent of treatment status (i.e., SPS intensity). In other words, we test if the conditional mean difference of each presupport covariate given the generalized propensity score is not different between farms belonging to a particular support interval and farms belonging to all other support intervals. Balancing tests are performed for each single variable included in the list of covariates, $X_{1}$ to $X_{10}$, and each mean support interval, $t_{1}$ to $t_{4}$. For each GPS block we test whether the mean difference of variables for farms belonging to the particular SPS intensity level are significantly different from those of farms with a different intensity level of support, but with the same GPS level.

The $t$-test results for each of the 10 covariates and each of the four groups of intervals are reported in Table A3 (for the full sample) and Table A7 (for subsamples). The results of the two-side $t$-tests show that in all support intervals the balancing property is satisfied at a high significance level (5\% for the full sample and $20 \%$ for both subsamples). This implies that, given the estimated generalized propensity scores, the means of the covariates used for the estimation of support effects do not differ significantly across various groups of farms with different levels of support.

Following equation [A8], the conditional expectation of the outcome indicator $Y$, change in land rent in 2007 relative to 2004 , is specified as a flexible function of its two arguments, $T_{i}$ and GPS, $R_{i}$ (i.e., a polynomial of a linear function of $T_{i}$ and a cubic function of $R_{i}$ ):

$Y_{i}=b_{0}+b_{1} T_{i}+b_{2} R_{i}+b_{3} R_{i}^{2}+b_{4} R_{i}^{3}+T_{i} R_{i}$.

The coefficients of model [A10] are estimated by ordinary least squares (OLS) using the observed $T_{i}$ and the estimated GPS $\left(R_{i}\right)$ from the previous steps. The estimation results are reported in Table A4 for 
the full sample and in Table A8 for subsamples. According to Hirano and Imbens (2004), the estimated coefficients do not have a direct interpretation, except that they serve to test whether all coefficients involving the GPS are equal to zero and can be interpreted as a test of whether the covariates introduce any bias.
Our results suggest that all coefficients involving the estimated GPS (linear, square, and cubic terms) are statistically significant. This implies that the sample selectivity and endogeneity are important and that the GPS estimation is relevant and significantly reduces them in the estimated response function.

Full Sample

TABLE A1

Estimates of the Support Equation for Full Sample

\begin{tabular}{|c|c|c|}
\hline & Coef. & Std. Err. \\
\hline \multicolumn{3}{|l|}{ Maximum likelihood equation } \\
\hline UAA per FL 2004 & $-0.0002005^{*}$ & 0.000103 \\
\hline Economic size per FL 2004 & $0.0002868 * *$ & 0.000101 \\
\hline Output per FL 2004 & $-1.50 \mathrm{e}-08$ & $9.48 \mathrm{e}-08$ \\
\hline Gross farm income per FL 2004 & $3.78 \mathrm{e}-09$ & $1.60 \mathrm{e}-07$ \\
\hline Liabilities per FL 2004 & $1.32 \mathrm{e}-07 * * *$ & $2.54 \mathrm{e}-08$ \\
\hline Total subsidies to gross farm income 2004 & 0.0026854 & 0.002732 \\
\hline Investment subsidies to net investment 2004 & -0.000793 & 0.002400 \\
\hline Coupled subsidies to gross investment 2004 & $3.94 \mathrm{e}-07$ & 0.002358 \\
\hline Rented land to UAA 2004 & $-0.244827 * * *$ & 0.030837 \\
\hline Entitlements per FL 2007 & $-3.28 \mathrm{e}-06^{* * *}$ & $1.14 \mathrm{e}-06$ \\
\hline Constant & $5.53674 * * *$ & 0.022214 \\
\hline \multicolumn{3}{|l|}{ Estimated standard deviation } \\
\hline Constant & $1.197378 * * *$ & 0.0066058 \\
\hline Observations & \multicolumn{2}{|c|}{16,428} \\
\hline
\end{tabular}

Note: FL, family labor; UAA, utilized agricultural area.

$* p<0.1$;** $p<0.05 ; * * * p<0.01$.

TABLE A2

Summary Statistics of the Distribution of the Generalized Propensity Score for Full Sample

\begin{tabular}{lccccc}
\hline \hline & Observations & Mean & Std. Dev. & Min. & Max. \\
\hline gps_1 & 16,428 & $2.8 \mathrm{e}-04$ & 0.0016 & 0.0000 & 0.2068 \\
gps_2 & 16,428 & 0.3254 & 0.0075 & 0.0003 & 0.3332 \\
gps_3 & 16,428 & 0.1458 & 0.0137 & 0.0000 & 0.3327 \\
gps_4 & 16,428 & 0.0664 & 0.0093 & 0.0000 & 0.3017 \\
\hline
\end{tabular}




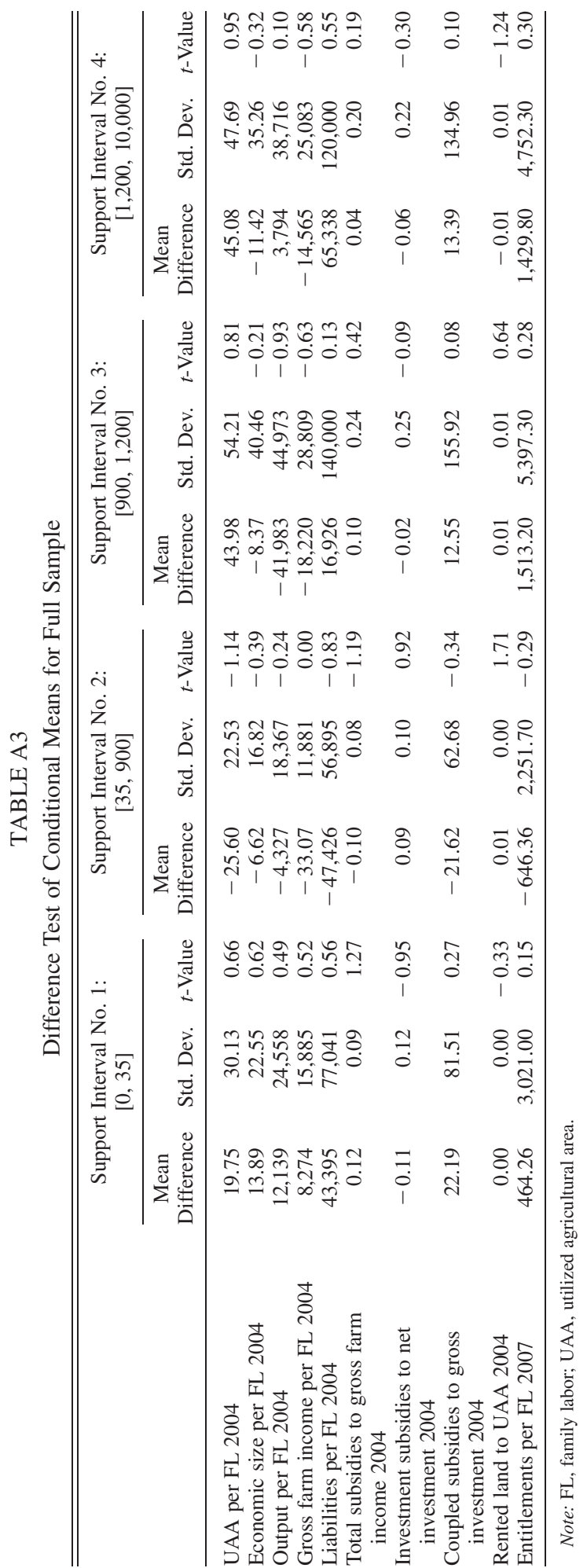


TABLE A4

GPS Matching Regression (Dependent Variable: Land Rent Difference 2007-2004) for Full Sample

\begin{tabular}{lrrrr}
\hline \hline & \multicolumn{1}{c}{ Coef. } & \multicolumn{1}{c}{ Std. Err. } & \multicolumn{1}{c}{$t$} & $P>|t|$ \\
\hline$T$ & -0.006 & 0.005 & -1.390 & 0.166 \\
$R$ & 761.395 & 199.622 & 3.810 & 0.000 \\
$R^{\wedge} 2$ & $-5,090.853$ & $1,343.682$ & -3.790 & 0.000 \\
$R^{\wedge} 3$ & $9,040.258$ & $2,417.125$ & 3.740 & 0.000 \\
$T^{*} R$ & 0.031 & 0.049 & 0.630 & 0.532 \\
Constant & -23.105 & 6.917 & -3.340 & 0.001 \\
Observations & 16,428 & & & \\
\hline
\end{tabular}

Note: Estimated equation: Rent difference $2007-2004=\mathrm{SPS}+\mathrm{GPS}+\mathrm{GPS}^{\wedge} 2+\mathrm{GPS}^{\wedge} 3+\mathrm{SPS} * \mathrm{GPS}$.

Hybrid and Decoupling Subsamples

TABLE A5

Estimates of the Support Equation for Hybrid and Decoupling Subsamples

\begin{tabular}{|c|c|c|c|c|}
\hline & \multicolumn{2}{|l|}{ Hybrid } & \multicolumn{2}{|c|}{ Decoupling } \\
\hline & Coef. & Std. Err. & Coef. & Std. Err. \\
\hline \multicolumn{5}{|l|}{ Maximum Likelihood Equation } \\
\hline UAA per FL 2004 & $-0.0005458 * * *$ & 0.00007 & $-0.0004173^{* * *}$ & 0.00011 \\
\hline Economic size per FL 2004 & $0.000291 * * *$ & 0.00006 & $0.0003253 * * *$ & 0.00006 \\
\hline Output per FL 2004 & $-0.00000091 * * *$ & 0.00000 & $-0.00000105^{* * *}$ & 0.00000 \\
\hline Gross farm income per FL 2004 & $0.00000196^{* * *}$ & 0.00000 & $0.00000212 * * *$ & 0.00000 \\
\hline Liabilities per FL 2004 & $0.0000000965^{* * *}$ & 0.00000 & $0.00000011^{* * *}$ & 0.00000 \\
\hline Total subsidies to gross farm income 2004 & 0.0004014 & 0.00173 & 0.003486 & 0.00281 \\
\hline Investment subsidies to net investment 2004 & 0.0009836 & 0.00185 & 0.000803 & 0.00194 \\
\hline Coupled subsidies to gross investment 2004 & $-6.33 \mathrm{E}-07$ & 0.00000 & $-6.39 \mathrm{E}-06$ & 0.00004 \\
\hline Rented land to UAA 2004 & 0.0285001 & 0.02452 & $-0.0527594 * *$ & 0.02879 \\
\hline Entitlements per FL 2007 & $-0.00000193 * * *$ & 0.00000 & $-0.00000356^{* * * *}$ & 0.00000 \\
\hline Constant & $5.645974 * * *$ & 0.01620 & $5.733992 * * *$ & 0.01946 \\
\hline \multicolumn{5}{|l|}{ Estimated Standard Deviation } \\
\hline Cons & $0.5426951 * * *$ & 0.00495 & $0.5699589 * * *$ & 0.00569 \\
\hline
\end{tabular}

Note: FL, family labor; UAA, utilized agricultural area.

TABLE A6

Summary Statistics of the Distribution of the Generalized Propensity Score for Hybrid and Decoupling Subsamples

\begin{tabular}{lccccc}
\hline \hline & Obs. & Mean & Std. Dev. & Min. & Max. \\
\hline Hybrid & & & & & \\
gps_1 & 5,999 & 0.0000 & 0.0000 & 0.0000 & 0.0028 \\
gps_2 & 5,999 & 0.7289 & 0.0367 & 0.0000 & 0.7351 \\
gps_3 & 5,999 & 0.0630 & 0.0208 & 0.0000 & 0.6742 \\
gps_4 & 5,999 & 0.0013 & 0.0112 & 0.0000 & 0.7329 \\
Decoupling & & & & & \\
gps_1 & & & & & \\
gps_2 & 5,018 & 0.0000 & 0.0001 & 0.0000 & 0.0044 \\
gps_3 & 5,018 & 0.6933 & 0.0385 & 0.0000 & 0.6999 \\
gps_4 & 5,018 & 0.0887 & 0.0251 & 0.0000 & 0.6504 \\
\hline
\end{tabular}




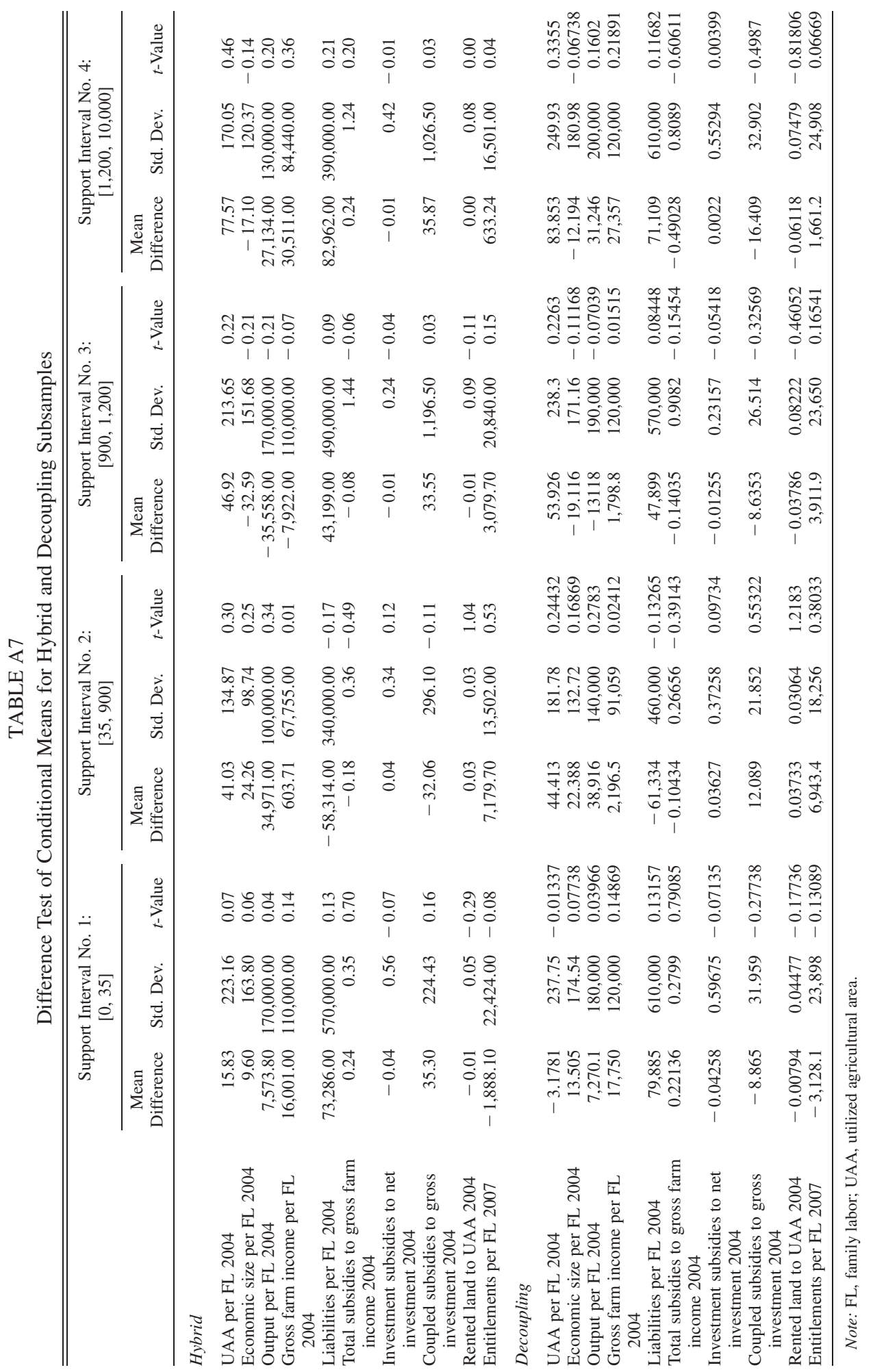


TABLE A8

GPS Matching Regression (Dependent Variable: Land Rent Difference 2007-2004) for Hybrid and Decoupling Subsamples

\begin{tabular}{lrrrr}
\hline \hline & \multicolumn{1}{c}{ Coef. } & Std. Err. & \multicolumn{1}{c}{$t$} & $P>|t|$ \\
\hline Hybrid & & & & \\
$T$ & 0.030 & 0.011 & 2.730 & 0.006 \\
$R$ & 241.262 & 155.049 & 1.560 & 0.120 \\
$R^{\wedge} 2$ & -603.651 & 414.701 & -1.460 & 0.146 \\
$R^{\wedge} 3$ & 450.098 & 323.787 & 1.390 & 0.165 \\
$T^{*} R$ & -0.021 & 0.050 & -0.430 & 0.665 \\
Constant & -38.615 & 17.133 & -2.250 & 0.024 \\
Decoupling & & & & \\
$T$ & 0.032 & 0.012 & 2.750 & 0.006 \\
$R$ & 216.439 & 187.077 & 1.160 & 0.247 \\
$R^{\wedge} 2$ & -714.653 & 534.105 & -1.340 & 0.181 \\
$R^{\wedge} 3$ & 635.644 & 440.257 & 1.440 & 0.149 \\
$T^{*} R$ & 0.019 & 0.058 & 0.340 & 0.736 \\
Constant & -37.604 & 18.590 & -2.020 & 0.043 \\
\hline
\end{tabular}

\section{Acknowledgments}

The authors acknowledge helpful comments from seminar participants in Pittsburgh and Zurich. The authors are grateful to the Microeconomic Analysis Unit L. 3 of the European Commission for granting access to the farm-level FADN data. The authors are solely responsible for the content of the paper. The views expressed are purely those of the authors and may not in any circumstances be regarded as stating an official position of the European Commission.

\section{References}

Ahearn, Mary C., Hisham El-Osta, and Joe Dewbre. 2006. "The Impact of Coupled and Decoupled Government Subsidies on Off-farm Labor Participation of U.S. Farm Operators." American Journal of Agricultural Economics 88 (2): 393-408.

Alston, Julian M., and Jennifer S. James. 2002. "The Incidence of Agricultural Policy." In Handbook of Agricultural Economics, Vol. 2B, ed. Bruce L. Gardner and Gordon C. Rausser, 1689-1749. Amsterdam: Elsevier.

Barnard, Charles H., Gerald Whittaker, David Westenbarger, and Mary Ahearn. 1997. "Evidence of Capitalization of Direct Government Payments into U.S. Cropland Values." American Journal of Agricultural Economics 79 (5): 1642-50.

Bhaskar, Arathi, and John C. Beghin. 2010. "Decoupled Farm Payments and the Role of Base Updating under Uncertainty." American Journal of Agricultural Economics 92 (3): 849-58.

Bia, Michela, and Allesandra Mattei. 2008. "A Stata Package for Estimation of the Dose-Response
Function through Adjustment for the Generalized Propensity Score." Stata Journal 8 (3): 354-73.

Breustedt, Gunnar, and Hendrik Habermann. 2011. "The Incidence of E.U. Per-Hectare Payments on Farmland Rental Rates: A Spatial Econometric Analysis of German Farm-Level Data." Journal of Agricultural Economics 62 (1): 225-43.

Carpentier, Alain, Alexandre Gohin, and Christoph Heinzel. 2012. "Production Effects of Direct Payments to Active Farmers: a Microeconomic Dynamic and Stochastic Analysis." Paper presented at the 123rd EAAE Seminar, Dublin, February 2324, 2012.

Ciaian, Pavel, and d'Artis Kancs. 2012. "The Capitalization of Area Payments into Farmland Rents: Micro Evidence from the New E.U. Member States." Canadian Journal of Agricultural Economics 60 (4): 517-40.

Ciaian, Pavel, d'Artis Kancs, and Johan F. M. Swinnen. 2008. "Static and Dynamic Distributional Effects of Decoupled Payments: Single Farm Payments in the European Union." LICOS Discussion Paper 207/2008. Leuven, Belgium: LICOS.

2010. E.U. Land Markets and the Common Agricultural Policy. Brussels: CEPS.

Ciaian, Pavel, and Johan F. M. Swinnen. 2006. "Land Market Imperfections and Agricultural Policy Impacts in the New E.U. Member States: A Partial Equilibrium Analysis." American Journal of Agricultural Economics 88 (4): 799-815.

- 2009. "Credit Market Imperfections and the Distribution of Policy Rents." American Journal of Agricultural Economics 91 (4): 1124-39.

Courleux, Frédéric, Hervé Guyomard, Fabrice Levert, and Laurent Piet. 2008. "How the E.U. Single 
Farm Payment Should be Modelled: Lump-Sum Transfers, Area Payments or ... What Else?" Working Paper SMART-LERECO 08-01. Rennes, France: INRA.

de Gorter, Harry. 1992. "Assessing the Transfer Efficiency of Agricultural Support Policies.” Report to the OECD. Paris: OECD.

de Gorter, Harry, and Karl D. Meilke. 1989. "Efficiency of Alternative Policies for the EC's Common Agricultural Policy." American Journal of Agricultural Economics 71 (3): 592-603.

Desquilbet, Marion, and Hervé Guyomard. 2002. "Taxes and Subsidies in Vertically Related Markets." American Journal of Agricultural Economics 84 (4): 1033-41.

Dewbre, Joe, Jesús Anton, and Wyatt Thompson. 2001. "The Transfer Efficiency and Trade Effects of Direct Payments." American Journal of Agricultural Economics 83 (5): 1204-14.

EUR-Lex. 2003. Council Regulation (EC) No 1782/ 2003. Official Journal of the European Union L 270, 29 September 2003. Luxemburg: Publication Office of the European Union.

- 2011. 2011 Budget. Official Journal of the European Union 15.03.2011. Luxemburg: Publication Office of the European Union.

European Commission. 2007. Agriculture in the European Union: Statistical and Economic Information 2007. Brussels: Directorate for Agriculture and Rural Development.

Gardner, Bruce. 1983. "Efficient Redistribution through Commodity Markets." American Journal of Agricultural Economics 65 (2): 225-34.

- 2002. "U.S. Commodity Policies and Land Prices." Working Paper 28560. College Park: Department of Agricultural and Resource Economics, University of Maryland.

Goodwin, Barry K., and Ashok K. Mishra. 2006. "Are 'Decoupled' Farm Program Payments Really Decoupled? An Empirical Evaluation." American Journal of Agricultural Economics 88 (1): 73-89.

Goodwin, Barry K., Ashok K. Mishra, and François N. Ortalo-Magné. 2003. "What's Wrong with Our Models of Agricultural Land Values?" American Journal of Agricultural Economics 85 (3): 74452.

Guyomard, Hervé, Chantal Le Mouël, and Alexandre Gohin. 2004. "Impacts of Alternative Agricultural Income Support Schemes on Multiple Policy Goals." European Review of Agricultural Economics 31 (2): 125-48.

Hirano, Keisuke, and Guido W. Imbens. 2004. "The Propensity Score with Continuous Treatments." In Applied Bayesian Modeling and Causal Inference from Incomplete-Data Perspectives, ed. Andrew Gelman and Xiao-Li Meng. West Sussex, England: Wiley InterScience.
Key, Nigel, and Michael J. Roberts. 2009. "Nonpecuniary Benefits to Farming: Implications for Supply Response to Decoupled Payments." American Journal of Agricultural Economics 91 (1): 1-18.

Kilian, Stefan, Jesús Antón, Klaus Salhofer, and Norbert Röder. 2012. "Impacts of 2003 CAP Reform on Land Rental Prices and Capitalization." Land Use Policy 29 (4): 789-97.

Kilian, Stefan, and Klaus Salhofer. 2008. "Single Payments of the CAP: Where Do the Rents Go?" Agricultural Economics Review 9 (2): 96-106.

Kirwan, Barrett E. 2009. "The Incidence of U.S. Agricultural Subsidies on Farmland Rental Rates." Journal of Political Economy 117 (1): 138-64.

Lagerkvist, Carl J. 2005. "Agricultural Policy Uncertainty and Farm Level Adjustments: The Case of Direct Payments and Incentives for Farmland Investment." European Review of Agricultural Economics 32 (1): 1-23.

Lence, Sergio H., and Ashok K. Mishra. 2003. "The Impacts of Different Farm Programs on Cash Rents." American Journal of Agricultural Economics 85 (3): 753-61.

McCorriston, Steve, and Ian M. Sheldon. 1991. "Government Intervention in Imperfectly Competitive Agricultural Input Markets." American Journal of Agricultural Economics 73 (3): 621-32.

Meléndez-Ortíz, Ricardo, Christophe Bellmann, and Jonathan Hepburn. 2009. Agricultural Subsidies in the WTO Green Box: Ensuring Coherence with Sustainable Development Goals. Cambridge: Cambridge University Press.

Munk, Knud. 1994. EC Agricultural Policy for the 21st Century. European Economy: Reports and Studies 4, European Commission. Luxembourg: Directorate-General for Economic and Financial Affairs.

Patterson, Brian, Steven D. Hanson, and Lindon J. Robison. 1998. "Characteristics of Farmland Leasing in the North Central United States." Staff Papers 11610. East Lansing: Michigan State University, Department of Agricultural, Food, and Resource Economics.

Patton, Myles, Philip Kostov, Seamus A. McErlean, and Joan Moss 2008. "Assessing the Influence of Direct Payments on the Rental Value of Agricultural Land." Food Policy 33 (5): 397-405.

Rainey, Ronald L., Bruce L. Dixon, Bruce L. Ahrendsen, Lucas D. Parsch, and Ralph W. Bierlen. 2005. "Arkansas Landlord Selection of LandLeasing Contract Type and Terms.” International Food and Agribusiness Management Review 8 (1): $1-19$.

Roberts, Michael J., Barrett Kirwan, and Jeffrey Hopkins. 2003. "The Incidence of Government Program Payments on Land Rents: The Challenges of 
Identification." American Journal of Agricultural Economics 85 (3): 762-69.

Robison, Lindon, and Jan L. Flora. 2003. "The Social Capital Paradigm: Bridging across Disciplines." American Journal of Agricultural Economics 85 (5): 1187-93.

Robison, Lindon J., Robert J. Myers, and Marcelo E. Siles. 2002. "Social Capital and the Terms of Trade for Farmland." Review of Agricultural Economics 24 (1): 44-58.

Salhofer, Klaus. 2001. "Elasticities of Substitution and Factor Supply Elasticities in European Agriculture: A Review of Past Studies." In OECD Market Effects of Crop Support Measures, 89119. Paris: OECD.

Salhofer, Klaus, and Erwin Schmid. 2004. "Distributive Leakages of Agricultural Support: Some Empirical Evidence." Agricultural Economics 30 (1): 51-63.

Sheldon, Ian M., Daniel H. Pick, and Steve McCorriston. 2001. "Export Subsidies and ProfitShifting in Vertical Markets." Journal of Agricultural and Resource Economics 26 (1): 125-41.

Siles, Marcelo, Lindon Robison, Bruce Johnson, Gary Lynne, and M. David Beveridge. 2000. "Farmland Exchanges: Selection of Trading Partners, Terms of Trade, and Social Capital." Journal of the ASFMRA 63 (1): 127-40.

Todd, Petra E. 2008. "Evaluating Social Programs with Endogenous Program Placement and Selection of the Treated." In Handbook of Development Economics, Vol. 4, ed. T. Paul Schultz and John A. Strauss, 3847-94. Amsterdam: Elsevier/NorthHolland.

Tsoodle, Leah J., Bill B. Golden, and Allen M. Featherstone. 2006. "Factors Influencing Kansas Agricultural Farm Land Values." Land Economics 82 (1): 124-39.

Vercammen, James. 2007. "Farm Bankruptcy Risk as a Link between Direct Payments and Agricultural Investment." European Review of Agricultural Economics, 34 (4): 479-500.

Weersink, Alfons, Steve Clark, Calum G. Turvey, and Rakhal Sarker. 1999. "The Effect of Agricultural Policy on Farmland Values." Land Economics 75 (3): 425-39.

Whitaker, James B. 2009. “The Varying Impacts of Agricultural Support Programs on U.S. Farm Household Consumption." American Journal of Agricultural Economics 91(3): 569-80.

World Trade Organization (WTO). 2003. Agriculture. WTO Agreements Series 3. Genève: World Trade Organization. 